\title{
Effect of Sodium Hypochlorite on Adhesive \\ Charactersitics of Dentin: A Systematic Review of Laboratory-Based Testing
}

\author{
Ensanya A. Abou Neel ${ }^{123 *}$, Jonathan C. Knowles ${ }^{3,4,5}$, Laurent Bozec ${ }^{6}$ \\ ${ }^{1}$ Division of Biomaterials, Restorative Dentistry Department, King Abdulaziz \\ University, Jeddah, Saudi Arabia,
}

${ }^{2}$ Biomaterials Department, Faculty of Dentistry, Tanta University, Tanta, Egypt,

${ }^{3}$ Biomaterials and Tissue Engineering Division, UCL, Eastman Dental Institute, 256 Gray's Inn Road, London, WC1X 8LD.

${ }^{4}$ The Discoveries Centre for Regenerative and Precision Medicine, UCL Campus, London, UK

${ }^{5}$ Department of Nanobiomedical Science \& BK21 Plus NBM Global Research Center for Regenerative Medicine, Dankook University, Cheonan, Korea

${ }^{6}$ Faculty of Dentistry, 124 Edward Street, University of Toronto, Toronto, ONM5G 1G6, Canada

${ }^{*}$ Corresponding author:

Prof. Ensanya A. Abou Neel

Division of Biomaterials,

Operative Dentistry Department,

Faculty of Dentistry,

King Abdulaziz University,

Jeddah, Saudi Arabia

P.O. Box: 80209

Zip Code : 21589

E-mails: eabouneel@kau.edu.sa; e.abouneel@ucl.ac.uk

\section{Acknowldgment:}




\section{Outline}

1. Introduction

2. Methods \& Study Design

2.1. Eligibility Criteria

2.2. Search Strategy

2.3. Risk of Bias Assessment

2.4. Data Extraction

2.5. Statistical Analysis

3. Results

3.1. Bonding to Coronal Dentin

3.2. Bonding to Pulp Chamber Dentin

3.3. Bonding to Radicular Dentin

3.4. Bonding to Root Canal Dentin

3.5. Risk of Bias Assessment

4. Discussion 


\section{Abstract}

Objective: The purpose of this review was to systematically summarize the outcomes of laboratory-based studies investigated the effect of sodium hypochlorite application on bond strength of dentin to various materials.

Data: A comprehensive literature search was conducted using PubMed, Google Scholar, Cochrane Library and OpenThesis database. Then a manual search was also carried out for references from identified articles.

Sources: The search followed the "Preferred Reporting Items for Systematic Reviews and Meta-Analyses (PRISMA)" statement. Two independent reviewers evaluated the collected studies for their eligibility according to the inclusion and exclusion criteria. Data abstraction and evaluation of risk of bias was then performed.

Study Selection: A total of 164 articles were assessed for eligibility. Only 69 met the inclusion criteria. Most included studies presented a low $(15.9 \%)$ to medium $(68.1 \%)$ risk of bias. Only $15.9 \%$ presented high risk of bias. Because of heterogeneity of the included studies, Meta-analysis was not performed.

Conclusion: The outcome from low or high risk of bias studies revealed that sodium hypochlorite has no effect on bond strength of coronal or root canal dentin. While that from medium risk studies showed a reduction in bond strength of dentin.

Key words: Sodium hypochlorite, bond strength, dentin, root canal fillings/sealers/posts and risk of bias. 


\section{Introduction}

Due to the complex anatomy of root canal, some areas of root canal dentin could remain untouched during instrumentation. Further effective cleaning is therefore an integral step for the success of endodontic treatments (2). Irrigants, rinses or inter-visit medications are commonly used to remove necrotic tissues and produce bacteria-free root canals $(3,4)$ - Fig. 1 (i). They also act as lubricants (5).

Sodium hypochlorite $(\mathrm{NaOCl})$ has been recognised as an effective antibacterial agent in 1843 when low rates of infection transmission was recorded between patients washed their hands with it. Its use as an irrigant in endodontics dated back to 1902 since then it has been routinely used for such purpose (6). It has an effective antibacterial action (7-10) and dissolves both pulpal remnants $(11,12)$ as well as the organic component of root canal dentin (3). Increasing the concentration of $\mathrm{NaOCl}$ helps to improve the tissue dissolution and debridement capacities $(13,14)$. Lowering the surface tension of $\mathrm{NaOCl}$ also helps to improve its penetration to those uninstrumented areas of root canals (15). Furthermore, $\mathrm{NaOCl}$ also helps in removal of the organic component of the smear layer, produced during filing and drilling of root canal (16). This layer is a film of debris attached to root canal dentin; it is composed of shredded dentin, bacteria, bacterial products, remants of pulp tissues and retained irrigants (17). It occludes the orifices of dentinal tubules, so its presence could adversely affect the penetration of root canal sealers and the formation of intertubular tages required for adhesion of filling materials to root canal dentin $(18,19)$. Also its removal could ensure elimination of bacteria and their products. Hence the survival and reproduction of bacteria under filling materials could be jeopardized. Since $\mathrm{NaOCl}$ can dissolve the organic content of the smear layer, a combination of both $\mathrm{NaOCl}$ and 
EDTA was found to be effective in removing both inorganic and organic content of the smear layer respectively (16). The concentration of both $\mathrm{NaOCl}$ and EDTA is very critical; erosion of root canal dentin could occure after the smear layer removal if the concentration is not well adjusted (20).

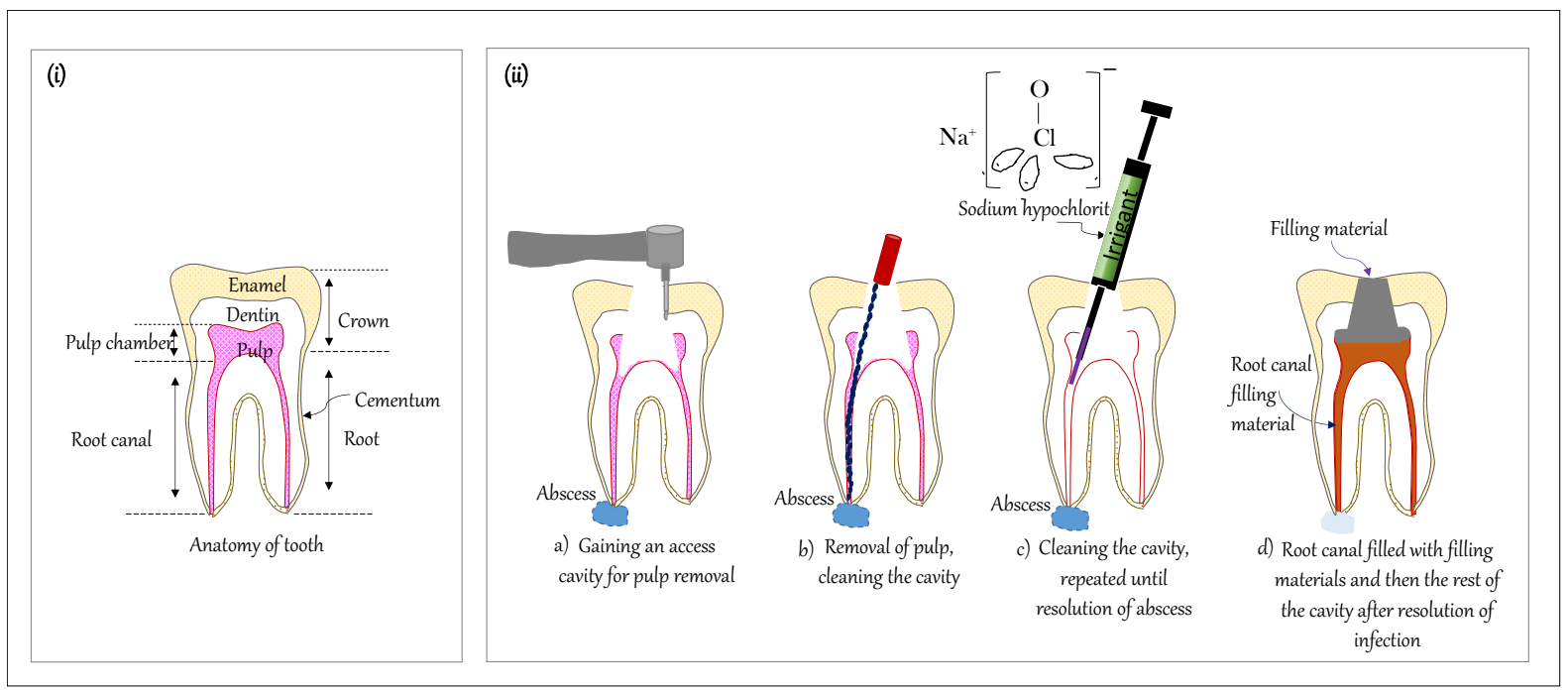

Fig. 1: Diagrammatic representation of (i) normal tooth anatomy. (ii) steps of endodontic treatment of tooth with periapical infection: in presence of infection eg, abscess; an access cavity is prepared a), pulp is then removed b); shaping and cleaning of root canal is repeated till infection subside; during this step $\mathrm{NaOCl}$ is usually used for irrigation of the root canal c), finally the root canal is filled with a root canal filling material eg, gutta percha and the rest of cavity is also filled with a restorative material eg composite d).

Dentin is composed of $20 \mathrm{wt} \%$ organix matrix (manily type I collagen) which substantially contributes to its mechanical properties. $\mathrm{NaOCl}$ is known to breakdown the long peptide chains. It also chlorinates terminal groups of protein which will then break down into other species. $\mathrm{NaOCl}$ may therefore adversely affect mechanical properties (eg, microhardness, elastic modulus and flexure strength) of dentin (3). Since $\mathrm{NaOCl}$ may alter the composition of dentin, its interaction (eg, bond strength) with the subsequent root filling materials could be affected. The long term success of post/core, for example, depends on the bonding of adhesive cement to root canal 
dentin. Improvement in bonding to root canal dentin increases the longevity of restorations (21-23). Lack of sealing ability of root canal sealers, used with root canal filling materials, or adhesive cements, used to bond post/core materials, could lead to microleagen and finaly premature failure of endodontic treatement (24).

The adhesive ability of any restoration can be used to predict its longevity that can be measured by bond strength test eg, microtensile, shear, pull out and push out test. The validity of these tests and their relevance to the clinical performance of any restoration is still questionable (25). The relevance of these tests to in vitro microleakage is also questionable (26). However, due to their simplicity, bond strength tests (eg macrobond) are still in use to measure the adhesion of restorative materials to tooth structures (25). Some of these tests (microtensile and microshear) also correlate better with longevity of restorations than others (macrotensile and macroshear) (27).

Not only the root canal dentin can be affected by irrigation/rinses/medications but also the coronal dentin (34). Furthermore, coronal dentin can be infected during root canal irrigation. Both conditions could affect the way the coronal dentin interact with the adhesive system and restorative materials used to restore the crown portion. Compromising the bond of restorative materials to coronal dentin will jeopridize the sealing ability of coronal restorations (35). A perfectly sealed coronal restoration is essential for increasing the longevity of an endodontically treated teeth. The main purposes behind a highly sealed coronal restoration are to avoid marginal leakage, increase the resistance of remaining tooth structure to fracture and restore the function and esthetics (36). For perfectly sealed coronal restoration, adhesives have been used with composite resins. Total etch and self etch adhesive systems are commonly used 
for such purpose. With total etch ( 3 step system), its application usually starts with $37 \%$ phosphoric acid etching followed by the primer and then bonding agent. Some total etch ( 2 step system) combines the primer and bonding agent together. Self etch on the other hand, skips the acid etching step. So the etchant could be combined with the primer (2 step system) or with both primer and bonding agent (one step system). The idea behind the use of dentin adhesives is to produce a strong, durable bond between resin and dentin. This bond will be formed when a monomer, having both hydrophilic and hydrophobic groups, penetrated dentin and polymerizes in situ. This resin-impregnation creates a transitional "hybrid" layer of resin-reinforced dentin. This hybrid layer is responsible for locking dentin with any other material on a molecular level creating a perfect seal against marginal leakage (37). Dentin hybridization, however, is a very sensitive technique (38). Recently, it has been shown that deproteinization of normal or acid etched dentin using sodium hypochlorite could be employed as an alternative method to the commonly used technique-sensitive dentin hybridization $(39,40)$.

Several studies reported the action of $\mathrm{NaOCl}$ on bond strength to dentin; there is however a significant controversy between these studies. Some studies reported that $\mathrm{NaOCl}$ improved the bond strength to dentin. They related this improvement to: (a) its deproteinizing action (dissolution and removal of exposed decalcified collagen produced by acid etching) thus producing a fresh mineralized matrix that bonded directly to the adhesive $(29,30)$ and (b) formation of an unusual bonding mechanism to dentin called a "reverse hybrid layer" where $\mathrm{NaOCl}$ can also dissolve collagen fibrils in the mineralized matrix left after acid etching producing submicron porosities into which the adhesive can penetrate forming this layer (30). Other studies suggested the opposite (ie, $\mathrm{NaOCl}$ reduces the bond strength to dentin). They related this to: (a) its 
deproteinizing action that produces a less receptive surface for bonding (31); (b) removal of collagen fibrils prevent the formation of a continuous hybrid layer (32); (c) the presence of remnants of $\mathrm{NaOCl}$ may interfere with the penetration of adhesive resins (32) and (c) its oxidizing action and hence an interference with the polymerization mechanism of adhesive resins (33). Accordingly, some authors recommended a delay of bonding for one week after root canal irrigation to provide enough time for elimination of the adverse effect of irrigants/rinses on dentin (28). This delaly in some cases is however impractical. In addition to this major controversy in the results, there are no systematic reviews published on the action of $\mathrm{NaOCl}$ on bond strength of dentin. Therefore, this systematic review aimed to summarize the outcomes of in vitro studies conducted on bond strength of dentin treated with sodium hypochlorite. It was conducted to answer the following research question (PICO statement is also included): Q1: Does the application of $\mathrm{NaOCl}$ have an effect on the bond strength of dentin? PICO statement: P/Population = dentin (whether coronal or root canal); I/Intervention = application of $\mathrm{NaOCl} ; \mathbf{C} /$ Comparison $=$ dentin or dentin irrigated with water or saline; O/Outcome $=$ effect on bond strength .

\section{Methods/Study Design}

This review has been conducted according to the PRISMA (Preferred Reporting Items for Systematic Reviews and Meta-analyses) statement.

\subsection{Eligibility Criteria}

In vitro studies reporting the bond strength to dentin treated with sodium hypochlorite were considered eligible for inclusion in this systematic review. Articles were considered eligible if they: 
a) Evaluated the effect of sodium hypochlorite applied (before or after etching) on bond strength (immediate or long term) of dentin (human or bovine; coronal or radicular or pulp chamber or root canal) to different materials (resin cements or endodontic fillings or posts).

b) Have a control group ( $\mathrm{NaOCl}$-untreated dentin, dentin irrigated with water or saline).

Articles that did not cover such data were excluded. Also in vitro studies that did not report the bond strength and present the control where other chemical irrigants (eg, chlorehexidine) used as controls were excluded. Non- English articles or those having authors' or editorial opinions were also excluded.

\subsection{Search Strategy}

A web-based search, conducted using PubMed and Google Scholar as research engines, was used to collect the research data. No time limitation was used during the search. The following key words were used for the search: (Sodium hypochlorite OR chemical irrigant OR deprotonizing agent* OR oxidizing agent) AND (Dentin bonding OR dentin adhesive* OR Dent* ${ }^{*}$ self-etch adhesive OR Dent ${ }^{*}$ etch and rinse adhesive OR resin cement) AND (resin composite OR endodontic filling OR root canal filling OR endodontic sealer OR root canal sealer). These key words were modified according to the database used for the search. The initial search was conducted in August 2016 and repeated in October 2017 before the final write-up. Furthermore, using a similar search, OpenThesis database was also used to collect relevant theses and dissertations. Reference list of all included studies were hand searched for additional articles. Consultation with endodontic experts was also obtained through personal correspondence. An example of search strategy used is given in Table 1. 
Table 1: An example of search strategy conducted in this systematic review (I) and category \& subcategory used for data extraction (II).

\begin{tabular}{|c|c|c|}
\hline No. & I. Search key words & Results \\
\hline$\# 1$ & $\begin{array}{l}\text { Sodium hypochlorite solution * OR sodium hypochlorite gel* root canal irrigation * } \\
\text { OR endodontic irrigation* OR hypochlorite* }\end{array}$ & 7385 \\
\hline$\# 2$ & $\begin{array}{l}\text { Dentin bonding* OR dental adhesives* OR dental adhesive }{ }^{*} \text { OR adhesive* OR } \\
\text { adhesives* OR etch and rinse* OR total etch* OR self etch }{ }^{*} \text { OR one step self etch* } \\
\text { OR two step self etch* three steps etch and rinse* OR bond strength* OR shear } \\
\text { bond strength* tensile bond strength* OR microtensile bond strength* }\end{array}$ & 2237 \\
\hline$\# 3$ & $\begin{array}{l}\text { Endodontic filling* OR root canal filling* OR root canal sealers* }{ }^{*} \text { OR endodontic } \\
\text { sealers }^{*} \text { OR endodontic post }{ }^{*}\end{array}$ & 6900 \\
\hline$\# 4$ & \#1 AND\#2 AND\#3 & 7 \\
\hline
\end{tabular}

II. Category \& sub-category used for data extraction

1. $\mathrm{NaOCl}:$

a) Form

b) Concentration

c) Time of application

2. Type of control

3. Method:

a) Source of dentin/location/preparation method

b) Step during which $\mathrm{NaOCl}$ applied

c) Type of adhesive

d) Materials bonded to dentin

e) Bond strength test

4. Outcome of $\mathrm{NaOCl}$ on bond strength in comparison to control

Two independent reviewers screened the obtained articles by the title. Any duplicate was eliminated and the abstract of relevant articles were further appraised for their eligibility. When the information provided in both titles and abstracts was not sufficient; full text was considered. The inclusion of articles was based on the agreement between the two reviewers. Any disagreement between the two reviewers was solved by discussion.

\subsection{Risk of Bias Assessment}

For quality assessment, the evaluation has been based on the presence of the following six parameters: a) presence of control, b) description of sample size, c) 
randomization of samples, d) procedures carried out by one operator, e) blinding of the operator and f) materials used according to manufacturers' instructions.

If the parameter under interest has been reported, the article had "Y" (ie, Yes); if not the article received "N" (ie, No). Articles reported one or two parameters were classified as "high risk of bias". Those reported three or four were classified as "medium risk of bias", while those reported five or six were classified as "low risk of bias" (41).

\subsection{Data Extraction}

Full articles with relevant information were obtained and data were extracted by the two reviewers according to specific criteria that were categorized as given in Table 1.

\subsection{Statistical Analysis}

Descriptive statistics were used to describe the data obtained from this review, but due to heterogeneity of the studies, Meta-analysis was not be performed. 


\section{Results}

There were 234 articles identified through the database searching. After exclusion of duplicate articles, only 164 articles were involved; 95 articles were further excluded after assessing their eligibility. Therefore, there were 69 articles which were assessed qualitatively throughout this review - Fig. 2.

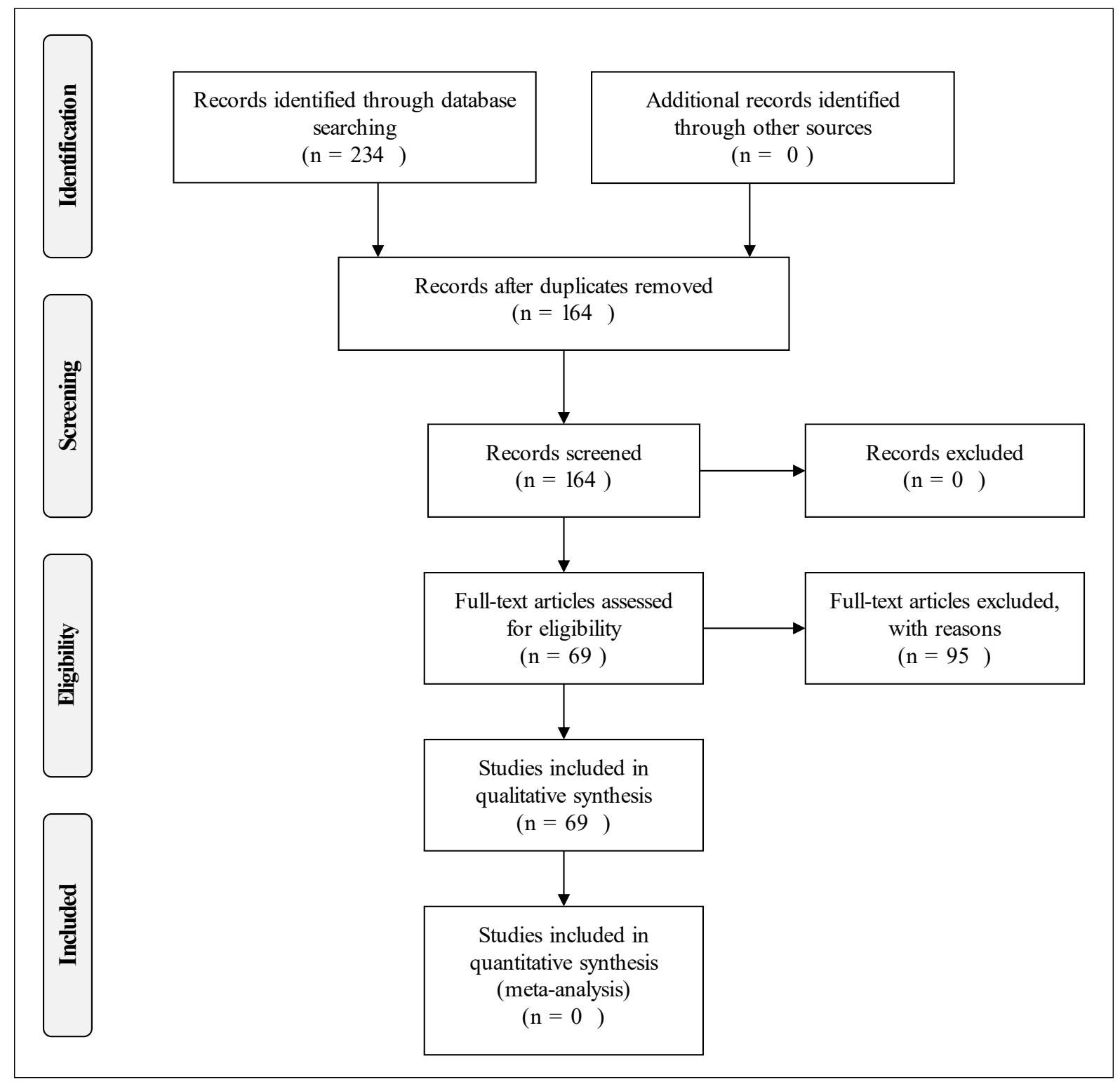

Fig. 2: PRISMA 2009 Flow Diagram 
Table 2 summarizes all the work carried out using sodium hypochlorite to treat dentin and highlights various methodologies used (eg, form/concentration/time of application/step during which $\mathrm{NaOCl}$ used, test method, type of adhesive used and type of materials bonded to treated dentin). Regardless of the main use of sodium hypochlorite as an irrigant solution for root canal during endodontic treatments, testing its effect on the bond strength to dentin did not only involve the use of root canal dentin but also the coronal or pulp chamber dentin as highlighted above. Furthermore, the use of sodium hypochlorite could be done after etching step. This includes two situations (a) when used with etch and rinse adhesive where etching is a separate step or (b) when used for deproteinization of acid etched dentin as an alterative to the technique-sensitive dentin hybridization (39) as explained above. The use of sodium hypocholorite could also be done before bonding. This includes two situations (a) before the application of self etch adhesive where there is no separate etching step or (b) when used to simulate what happens clinically where coronal dentin can be contaminated with sodium hypochlorie during root canal irrigation.

Diagrammatic representation of the different methods used to prepare samples for testing the effect of $\mathrm{NaOCl}$ on bond strength of different materials to dentin is presented in Fig. 3 (i-v). 


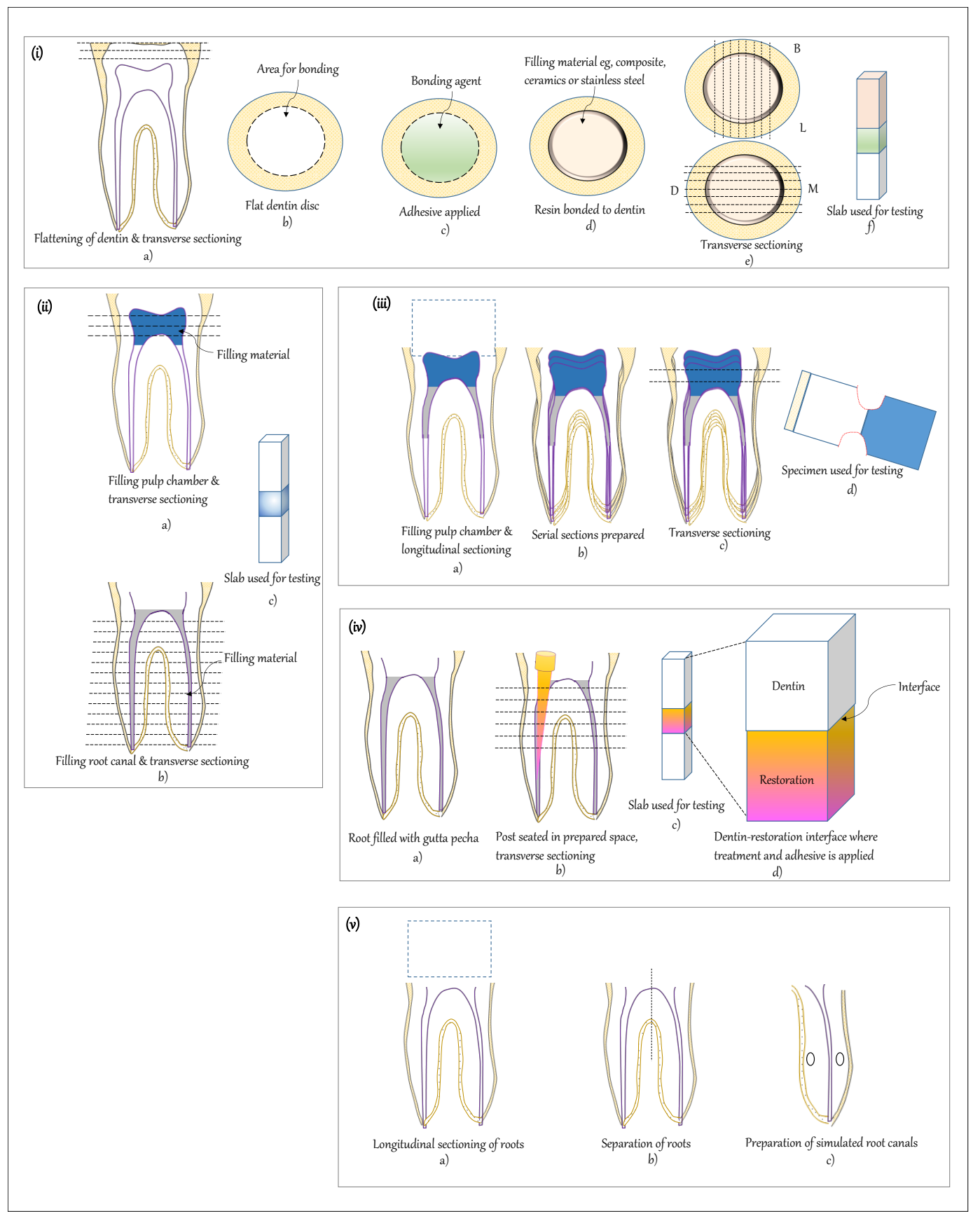

Fig 3: Different methods used to prepare samples for testing the adhesion of filling materials to $\mathrm{NaOCl}$-treated dentin; (i) This can be done by using coronal dentin after its flattening a) and preparing discs b) upon which the adhesive is applied c) then the filling material bonded to it d) then sectioning bucco-lingually or mesio-distally e) to prepare slabs used for testing f); (ii) Others rely on filling the pulp chamber a) or root canal b) then transvers sectioning is carried out to prepare slabs used for testing c); (iii) Sometimes longitudinal sections are performed after filling the pulp chamber a) to prepare serial sections $b$ ) that further cut transversally c) to prepare hourglass specimens used for testing d). (iv) Also, the root canal can be filled with gutta percha a), then a preparation is made within filled root canal to receive a post b), and then transverse sectioning is done to prepare slabs for testing c). In all cases, at the restoration-dentin interface, the dentin treatment and adhesive systems are performed d). (v) In some cases, simulated root canal cavities were prepared in radicular dentin at an equal distance between the dentin and root canal wall (a-c). 
Fig. 4(a) summarizes the distribution of number of cases according to the site from which dentin was used for testing the effect of $\mathrm{NaOCl}$ on bond strength ie, whether it is coronal (CD), pulp chamber (PCD) or root canal dentin (RCD). As seen $51 \%$ of cases used coronal dentin; $43 \%$ used root canal dentin and only $6 \%$ used pulp chamber dentin. Fig. 4(b) shows the distribution of the number of cases according to the step during which $\mathrm{NaOCl}$ was applied. Generally, $69 \%$ of cases applied $\mathrm{NaOCl}$ before the application of the adhesive (bonding system) to dentin; $31 \%$, applied $\mathrm{NaOCl}$ after etching (the first step of bonding) of dentin. When coronal dentin was used, most of the cases applied $\mathrm{NaOCl}$ after etching (45\%); the opposite is true for root canal dentin (ie, $20 \%$ of cases utilized $\mathrm{NaOCl}$ after etching). $\mathrm{NaOCl}$-treated coronal dentin was usually bonded to filling materials (eg, composites); $\mathrm{NaOCl}$-treated root canal dentin was usually bonded to root canal filling materials eg, gutta percha (42), resin cements (43) or posts (44). 


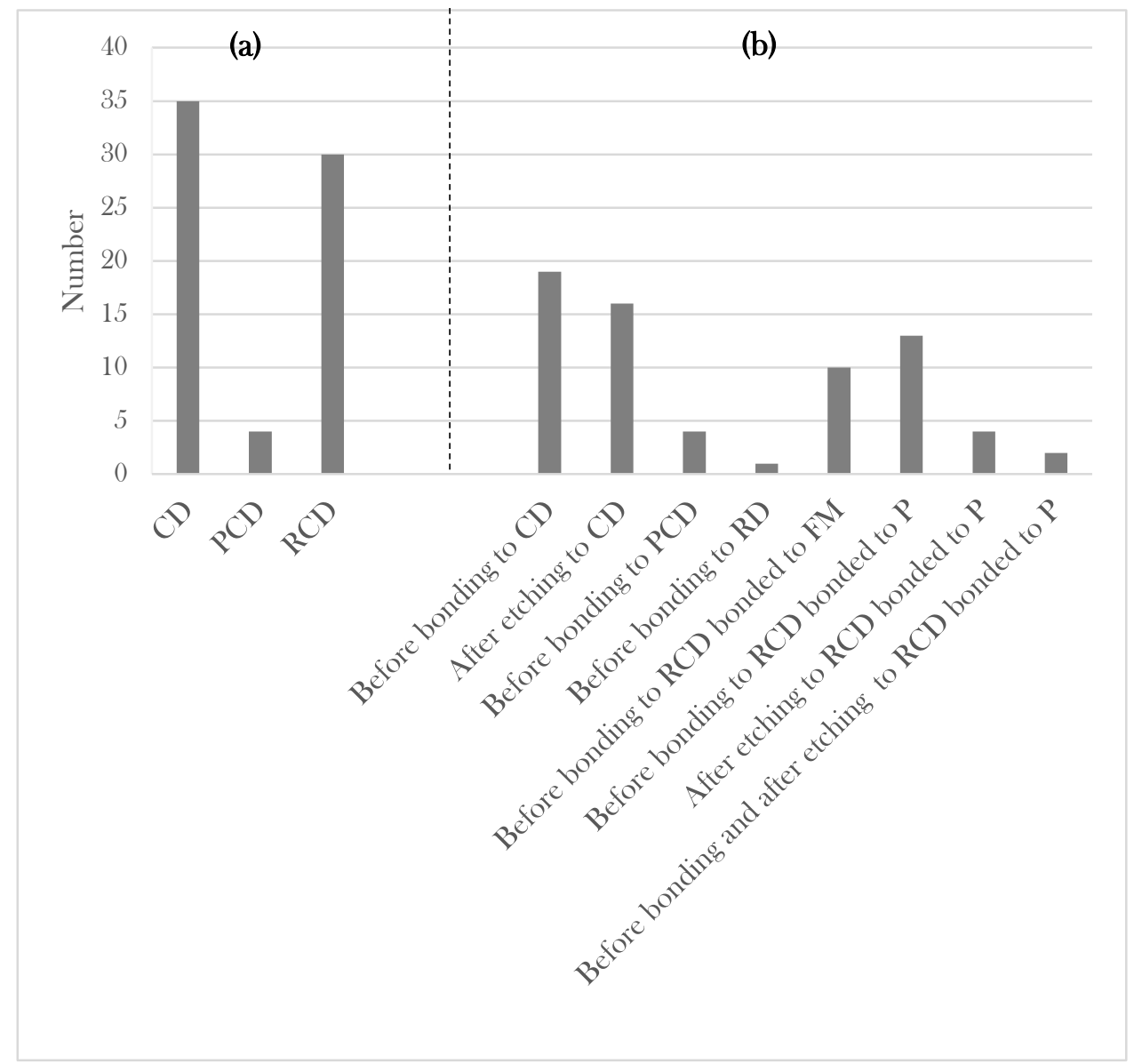

Fig. 4: Distribution of cases according to the site from which dentin was used ie, whether it is coronal (CD), pulp chamber (PCD) or root canal dentin (RCD) (a); steps during which $\mathrm{NaOCl}$ was applied (b). RD: radicular dentin (ie, simulated root canals).

FM: filling materials. $P$ : posts. 
Table 2: The effect of $\mathrm{NaOCl}$ application on bond strength to dentin. HF: hydroflouric acid. CEJ: cemento-enamel junction. ${ }^{+}$identifies all factors under bond strength testing methods while * identifies all factors under $\mathrm{NaOCl}$.

\begin{tabular}{|c|c|c|c|c|c|c|c|c|c|c|}
\hline Author & $\begin{array}{c}\text { +Step during } \\
\text { which } \mathrm{NaOCl} \\
\text { used }\end{array}$ & ${ }^{*}$ Form of $\mathrm{NaOCl}$ & $\begin{array}{c}\text { *Concentration } \\
\text { of } \mathrm{NaOCl} \\
(\%)\end{array}$ & $\begin{array}{l}\text { *Time of } \\
\text { application } \\
\text { of } \mathrm{NaOCl} \\
(\mathrm{min})\end{array}$ & $\begin{array}{l}\text { Type of } \\
\text { Control }\end{array}$ & $\begin{array}{l}\text { +Bond } \\
\text { strength } \\
\text { test }\end{array}$ & $\begin{array}{l}\text { +Source of dentin, } \\
\text { location \& preparation } \\
\text { method }\end{array}$ & + Type of adhesive & $\begin{array}{c}\text { +Material bonded to } \\
\text { dentin }\end{array}$ & $\begin{array}{l}\text { Outcome of } \\
\mathrm{NaOCl} \text { on bond } \\
\text { strength in } \\
\text { comparison to } \\
\text { control }\end{array}$ \\
\hline \multirow{3}{*}{$\begin{array}{l}\text { Francescantonio et al., } \\
(45)\end{array}$} & \multirow{3}{*}{$\begin{array}{l}\text { After etching } \\
\text { with } \mathrm{H} 3 \mathrm{PO} 4\end{array}$} & \multirow{3}{*}{ Gel } & \multirow{3}{*}{10} & \multirow{3}{*}{1} & \multirow{3}{*}{$\begin{array}{l}\text { Etched } \\
\text { dentin }\end{array}$} & \multirow{3}{*}{ Microtensile } & \multirow{3}{*}{$\begin{array}{l}\text { Human } 3^{\text {rd }} \text { molars, } \\
\text { coronal dentin }\end{array}$} & One Step Plus (etch \& rinse) & Aelite LS & Decrease \\
\hline & & & & & & & & Clearfil Photo Bond (etch \& rinse) & Clearfil Majesty & Decrease \\
\hline & & & & & & & & Clearfil SE Bond (self-etch) & Clearfil Majesty & No change \\
\hline \multirow{3}{*}{ Prati et al., (30) } & \multirow{3}{*}{$\begin{array}{l}\text { After etching } \\
\text { with } \\
35 \% \mathrm{H} 3 \mathrm{PO} 4 \\
\text { for 20s }\end{array}$} & \multirow{3}{*}{ Gel } & \multirow{3}{*}{1.5} & \multirow{3}{*}{2} & \multirow{3}{*}{$\begin{array}{l}\text { Etched } \\
\text { dentin }\end{array}$} & \multirow{3}{*}{$\begin{array}{c}\text { Shear } \\
\text { (immediate) }\end{array}$} & \multirow{3}{*}{$\begin{array}{l}\text { Human } 3^{\text {rd }} \text { molars, } \\
\text { coronal dentin }\end{array}$} & Optibond FL & \multirow{3}{*}{ Z100 (composite resin) } & Increase \\
\hline & & & & & & & & $\begin{array}{l}\text { Scothcbond MP } \\
\text { Single Bond }\end{array}$ & & $\begin{array}{l}\text { Decrease } \\
\text { Decrease }\end{array}$ \\
\hline & & & & & & & & Prime \& Bond 2 & & No change \\
\hline $\begin{array}{l}\text { Uceda-Gomez et al., } \\
\text { (46) }\end{array}$ & $\begin{array}{l}\text { After etching } \\
\text { with } 32 \% \\
\text { H3PO4 }\end{array}$ & Solution & 10 & 1 & $\begin{array}{l}\text { Etched } \\
\text { dentin }\end{array}$ & Microtensile & $\begin{array}{l}\text { Human molars, coronal } \\
\text { dentin, longitudinal } \\
\text { sections of teeth } \\
\text { (superficial vs deep } \\
\text { dentin ie apical vs } \\
\text { occlusal dentin) }\end{array}$ & One Step & Z100 (composite resin) & Decrease \\
\hline Osorio et al., (47) & $\begin{array}{l}\text { After etching } \\
\text { with } 35 \% \\
\text { H3PO4 for } \\
15 \text { s } \\
\end{array}$ & - & 5 & 2 & $\begin{array}{l}\text { Etched } \\
\text { dentin }\end{array}$ & Shear & $\begin{array}{l}\text { Human } 3^{\text {rd }} \text { molars, } \\
\text { coronal dentin }\end{array}$ & Single Bond & Z100 (composite resin) & Decrease \\
\hline \multirow[b]{2}{*}{ Yiu et al.,(48) } & \multirow[b]{2}{*}{ After etching } & \multirow[b]{2}{*}{-} & \multirow[b]{2}{*}{5} & \multirow{2}{*}{10} & \multirow[b]{2}{*}{$\begin{array}{l}\text { Etched } \\
\text { dentin }\end{array}$} & \multirow[b]{2}{*}{ Microtensile } & \multirow[b]{2}{*}{$\begin{array}{l}\text { Human } 3^{\text {rd }} \text { molars, } \\
\text { coronal dentin }\end{array}$} & One Step (single bottle) & \multirow[b]{2}{*}{$\begin{array}{l}\text { Renamel Sculpt } \\
\text { (composite resin) }\end{array}$} & \multirow[b]{2}{*}{ Decrease } \\
\hline & & & & & & & & $\begin{array}{l}\text { Gluma Comfort Bond }+ \\
\text { Desensitizer (single bottle) }\end{array}$ & & \\
\hline Saboia et al., (49) & $\begin{array}{l}\text { After etching } \\
\text { with } 35 \% \\
\text { H3PO4 for } \\
15 \text { s }\end{array}$ & Solution & 10 & 1 & $\begin{array}{l}\text { Etched } \\
\text { dentin }\end{array}$ & Microtensile & $\begin{array}{l}\text { Human } 3^{\text {rd }} \text { molars, } \\
\text { coronal dentin }\end{array}$ & XP-Bond (2-step etch \& rinse) & $\begin{array}{l}\text { Filtek Z250 (mcirohybrid } \\
\text { composite resin) }\end{array}$ & Decrease \\
\hline Baseggio et al., (50) & $\begin{array}{l}\text { After etching } \\
\text { with } 35 \% \\
\text { H3PO4 gel for } \\
\text { 20s } \\
\end{array}$ & - & 10 & 1 & $\begin{array}{l}\text { Etched } \\
\text { dentin }\end{array}$ & Microtensile & $\begin{array}{l}\text { Human } 3^{\text {rd }} \text { molars, } \\
\text { coronal dentin }\end{array}$ & Single Bond & Z100 (composite resin) & Decrease \\
\hline dos Santos et al., (51) & $\begin{array}{l}\text { After etching } \\
\text { with } 35 \% \\
\text { H3PO4 for } \\
15 \text { s } \\
\end{array}$ & Solution & 10 & 1 & $\begin{array}{l}\text { Etched } \\
\text { dentin }\end{array}$ & Shear & $\begin{array}{l}\text { Bovine incisors, coronal } \\
\text { dentin }\end{array}$ & Single Bond & Z100 (composite resin) & Decrease \\
\hline \multirow[b]{2}{*}{ Perdigão et al., (52) } & \multirow{2}{*}{$\begin{array}{l}\text { After etching } \\
\text { with } 34 \% \\
\text { H3PO4 for } \\
15 \text { s }\end{array}$} & \multirow[b]{2}{*}{ Gel } & \multirow[b]{2}{*}{10} & \multirow[b]{2}{*}{$1 / 4,1 / 2 \& 1$} & \multirow[b]{2}{*}{$\begin{array}{l}\text { Etched } \\
\text { dentin }\end{array}$} & & & Prime\&Bond NT (total-etch) & Surefil (composite resin) & Decrease with \\
\hline & & & & & & Shear & Bovine, coronal dentin & Single Bond (total-etch) & Z100 (composite resin) & \\
\hline Uceda-Gomez et al., & $\begin{array}{l}\text { After etching } \\
\text { with } 37 \% \\
\text { H3PO4 }\end{array}$ & & & & Etched & & & Single Bond (etch \& rinse) & & \\
\hline (53) & $\begin{array}{l}\text { After etching } \\
\text { with } 32 \% \\
\text { H3PO4 }\end{array}$ & Solution & 10 & 1 & dentin & Microtensile & $\begin{array}{l}\text { Human } 3^{\text {rd }} \text { molars, } \\
\text { coronal dentin }\end{array}$ & One Step (etch \& rinse) & Z250 (composite resin) & No change \\
\hline Manjunath \& Vinutha & $\begin{array}{l}\text { After etching } \\
\text { with 35\% }\end{array}$ & - & 5.25 & 1 & Etched & Shear & Human premolars, & $\begin{array}{l}\text { Adper Single Bond } 2 \text { (single } \\
\text { bottle) }\end{array}$ & Z100 (composite resin) & Increase \\
\hline 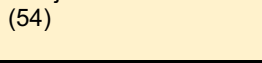 & $\begin{array}{l}\mathrm{H} 3 \mathrm{PO} 4 \text { for } \\
15 \mathrm{~s}\end{array}$ & & & & dentin & & coronal dentin & Excite (single bottle) & $\begin{array}{l}\text { TeEconom (composite } \\
\text { resin) }\end{array}$ & \\
\hline Correr et al., (55) & After etching & & & & & & & Single Bond & & \\
\hline & with $35 \%$ & Solution & 10 & 1 & $\begin{array}{l}\text { Etched } \\
\text { dentin }\end{array}$ & Shear & $\begin{array}{l}\text { Human primary molars, } \\
\text { coronal dentin }\end{array}$ & Prime \& Bond 2.1 & $\begin{array}{l}\text { Filtek Z250 (composite } \\
\text { resin) }\end{array}$ & No change \\
\hline
\end{tabular}




\begin{tabular}{|c|c|c|c|c|c|c|c|c|c|c|}
\hline & $\begin{array}{l}\mathrm{H} 3 \mathrm{PO} 4 \text { for } \\
15 \mathrm{~s}\end{array}$ & & & & & & & & & \\
\hline \multirow{3}{*}{ Montagner et al., (56) } & \multirow{3}{*}{$\begin{array}{l}\text { After etching } \\
\text { with } 35 \% \\
\text { H3PO4 for } \\
\text { 15s }\end{array}$} & \multirow{3}{*}{ Solution } & \multirow{3}{*}{10} & \multirow{3}{*}{1} & \multirow{3}{*}{$\begin{array}{l}\text { Etched } \\
\text { dentin }\end{array}$} & \multirow{3}{*}{ Push out } & \multirow{3}{*}{$\begin{array}{l}\text { Human } 3^{\text {rd }} \text { molars, } \\
\text { coronal dentin (circular } \\
\text { cavities in superficial \& } \\
\text { deep occlusal \& proximal } \\
\text { surfaces) }\end{array}$} & $\begin{array}{l}\text { Adper }{ }^{\mathrm{TM}} \text { Single Bond } 2 \text { (etch \& } \\
\text { rinse) }\end{array}$ & \multirow{3}{*}{$\begin{array}{l}\text { Filtek TM Z250 } \\
\text { (composite resin) }\end{array}$} & \multirow{3}{*}{ No change } \\
\hline & & & & & & & & Clearfil ${ }^{\top M}$ SE Bond (self-etch) & & \\
\hline & & & & & & & & $\begin{array}{l}\text { Adper TM SE Plus (self-etch) } \\
\text { G-Bond TM (self-etch) }\end{array}$ & & \\
\hline \multirow{2}{*}{ Lisboa et al., (57) } & \multirow{2}{*}{$\begin{array}{l}\text { After etching } \\
\text { with } 34 \% \\
\text { H3PO4 for } \\
15 \mathrm{~s} \\
\end{array}$} & \multirow{2}{*}{ - } & \multirow[t]{2}{*}{5} & \multirow{2}{*}{2} & \multirow{2}{*}{$\begin{array}{l}\text { Untreated } \\
\text { dentin }\end{array}$} & \multirow{2}{*}{ Shear } & \multirow[t]{2}{*}{$\begin{array}{l}\text { Human } 3^{\text {rd }} \text { molars, } \\
\text { coronal dentin }\end{array}$} & $\begin{array}{l}\text { Rely X Unicem (self-adhesive resin } \\
\text { cement) }\end{array}$ & $\begin{array}{l}\text { Rely } X \text { Unicem (self- } \\
\text { adhesive resin cement) }\end{array}$ & No change \\
\hline & & & & & & & & $\begin{array}{l}\text { BisCem (self-adhesive resin } \\
\text { cement) }\end{array}$ & $\begin{array}{l}\text { BisCem (self-adhesive } \\
\text { resin cement) }\end{array}$ & Increase \\
\hline Aguilera et al., (58) & $\begin{array}{l}\text { After etching } \\
\text { with } 35 \% \\
\text { H3PO4 } \\
\end{array}$ & Solution & 5 & 2 & $\begin{array}{l}\text { Etched } \\
\text { dentin }\end{array}$ & Shear & $\begin{array}{l}\text { Human } 3^{\text {rd }} \text { molars, } \\
\text { coronal dentin }\end{array}$ & Prime \& Bond NT & $\begin{array}{l}\text { Tetric Ceram (composite } \\
\text { resin) }\end{array}$ & No change \\
\hline \multirow{4}{*}{ de-Souza et al., (59) } & $\begin{array}{l}\text { After etching } \\
\text { with } 35 \% \\
\text { H3PO4 for } \\
\text { 15s } \\
\end{array}$ & \multirow{4}{*}{ Solution } & \multirow{4}{*}{5} & \multirow{4}{*}{2} & \multirow{4}{*}{$\begin{array}{l}\text { Etched } \\
\text { dentin }\end{array}$} & \multirow{4}{*}{ Microtensile } & \multirow{4}{*}{$\begin{array}{l}\text { Human } 3^{\text {rd }} \text { molars, } \\
\text { coronal dentin }\end{array}$} & Single Bond ${ }^{\top M}$ (total etch) & $\begin{array}{l}\text { Filtek } k^{\top M} \text { Z250 (composite } \\
\text { resin) }\end{array}$ & Decrease \\
\hline & $\begin{array}{l}\text { After etching } \\
\text { with } 34 \% \\
\text { H3PO4 for } \\
15 \text { s }\end{array}$ & & & & & & & Prime \& Bond $\mathrm{NT}^{\mathrm{TM}}$ (total etch) & $\begin{array}{l}\text { Esthet }{ }^{\oplus} \times \text { (composite } \\
\text { resin) }\end{array}$ & Increase \\
\hline & $\begin{array}{l}\text { After etching } \\
\text { with } 15 \% \\
\text { H3PO4 for } \\
30 \text { s } \\
\end{array}$ & & & & & & & One Coat Bond (total etch) & $\begin{array}{l}\text { Fill Magin (composite } \\
\text { resin) }\end{array}$ & No change \\
\hline & $\begin{array}{l}\text { After etching } \\
\text { with } 35 \% \\
\text { H3PO4 for } \\
\text { 15s } \\
\end{array}$ & & & & & & & $P Q 1^{\mathrm{TM}}$ & Vit-I-escence ${ }^{T M}$ & Increase \\
\hline \multirow[t]{2}{*}{ Sauro et al., (60) } & After etching & \multirow[t]{2}{*}{-} & \multirow[t]{2}{*}{0.5} & \multirow[t]{2}{*}{$1 / 2$} & \multirow{2}{*}{$\begin{array}{l}\text { Etched } \\
\text { dentin }\end{array}$} & \multirow[t]{2}{*}{ Microtneisle } & Human $3^{\text {rd }}$ molars, & Schotchbond 1XT (etch \& rinse) & Filtek Supreme $X \mathrm{~T}^{\mathrm{TM}}$ & No change \\
\hline & $\begin{array}{l}\text { with } 35 \% \\
\text { H3PO4 for } \\
15 \text { s } \\
\end{array}$ & & & & & & coronal dentin & Optibond Solo Plus (etch \& rinse) & $\begin{array}{l}\text { (flowable composite } \\
\text { resin) }\end{array}$ & \\
\hline Goncalves et al., (61) & $\begin{array}{l}\text { After etching } \\
\text { with } 37 \% \\
\text { H3PO4 for } \\
15 \text { s } \\
\end{array}$ & Solution & 10 & 1 & $\begin{array}{l}\text { Etched } \\
\text { dentin }\end{array}$ & Microtensile & $\begin{array}{l}\text { Bovine incisors, coronal } \\
\text { dentin }\end{array}$ & Prime \& Bond NT & $\begin{array}{l}\text { TPH Spectrum } \\
\text { (microhybrid composite } \\
\text { resin) }\end{array}$ & No change \\
\hline & & & & & & & & $\begin{array}{l}\text { Gluma One Bond } \\
\text { Prime \& Bond } 2.1\end{array}$ & & \\
\hline Arias et al., (62) & $\begin{array}{l}\text { After etching } \\
\text { with } 36 \%\end{array}$ & Gel & 10 & 1 & Etched & Shear & Bovine incisor, coronal & $\begin{array}{l}\text { Single Bond } \\
\text { Prime \& Bond NT }\end{array}$ & Z100 (composite resin) & No change \\
\hline & $\mathrm{H} 3 \mathrm{PO} 4$ for & & & & dentin & & dentin & Gluma One Bond & & Increase \\
\hline & & Solution & & & & & & Prime \& Bond 2.1 & & \\
\hline & & & & & & & & Single Bond & & No change \\
\hline & & & & & & & & Prime \& Bond NT & & \\
\hline & & & & $1 / 4$ & & & & Bond Force (self-etch) & & $\begin{array}{c}\text { Increase for } \\
\text { caries affected } \\
\text { dentin }\end{array}$ \\
\hline Taniguchi et al., (63) & Before & Solution & 6 & & $\begin{array}{l}\text { Dentin } \\
\text { rinsed with }\end{array}$ & Microtensile & Human molars, coronal & & Clearfil AP-X (composite & $\begin{array}{l}\text { No change for } \\
\text { normal dentin }\end{array}$ \\
\hline & bonding & & & $1 / 2$ & & & dentın & Clearfil Protect Bond (self-etch) & & $\begin{array}{l}\text { No change for } \\
\text { caries affected } \\
\text { dentin) }\end{array}$ \\
\hline & & & & & & & & & & $\begin{array}{l}\text { Decrease for } \\
\text { normal dentin }\end{array}$ \\
\hline & & & & & & & & Variolink II (total-etch) & & N0 change \\
\hline & & & & & & & & Cealrfill SA Cement (self-etch) & & Decrease \\
\hline
\end{tabular}




\begin{tabular}{|c|c|c|c|c|c|c|c|c|c|c|}
\hline \multirow[t]{3}{*}{ Stevens et al., (64) } & \multirow[t]{3}{*}{$\begin{array}{l}\text { Before } \\
\text { bonding }\end{array}$} & \multirow[t]{3}{*}{ Solution } & \multirow[t]{3}{*}{6} & \multirow[t]{3}{*}{20} & \multirow[t]{3}{*}{$\begin{array}{l}\text { Untreated } \\
\text { dentin }\end{array}$} & \multirow[t]{3}{*}{$\begin{array}{c}\text { Shear } \\
\text { (immediate) }\end{array}$} & \multirow[t]{3}{*}{$\begin{array}{l}\text { Human molars \& } \\
\text { premolars, coronal dentin }\end{array}$} & $\begin{array}{l}\text { Clearfill Esthetic Cement EX (self- } \\
\text { etch) }\end{array}$ & \multirow{3}{*}{$\begin{array}{l}\text { Ceramic rod etched with } \\
4.9 \% \mathrm{HF} \text { acid for } 20 \mathrm{~s} \\
\text { and silanated with } \\
\text { Monobond Plus for } 1 \mathrm{~min}\end{array}$} & \multirow{2}{*}{$\begin{array}{l}\text { N0 change } \\
\text { Decrease }\end{array}$} \\
\hline & & & & & & & & $\begin{array}{l}\text { SpeedCEM (self-etch, self- } \\
\text { adhesive) }\end{array}$ & & \\
\hline & & & & & & & & Multilink (self-etch, self-adhesive) & & No change \\
\hline Cecchin et al., (65) & $\begin{array}{l}\text { Before } \\
\text { bonding }\end{array}$ & Solution & 1 & $\begin{array}{l}5 \mathrm{ml} \text { every } \\
5 \mathrm{~min} \text { for } \\
60 \mathrm{~min}\end{array}$ & $\begin{array}{l}\text { Untreated } \\
\text { dentin }\end{array}$ & Microtensile & $\begin{array}{l}\text { Human } 3^{\text {rd }} \text { molars, } \\
\text { coronal dentin, hourglass } \\
\text { samples }\end{array}$ & Xeno III (self-etch) & Z250 (composite resin) & Increase \\
\hline \multirow{3}{*}{ Hassan et al., (66) } & \multirow{3}{*}{$\begin{array}{l}\text { Before } \\
\text { bonding }\end{array}$} & \multirow{3}{*}{ - } & \multirow{3}{*}{4} & \multirow{3}{*}{$1 / 3$} & \multirow{3}{*}{$\begin{array}{l}\text { Untreated } \\
\text { dentin }\end{array}$} & \multirow{3}{*}{ Shear } & \multirow{3}{*}{$\begin{array}{l}\text { Human molars, coronal } \\
\text { dentin }\end{array}$} & & $\begin{array}{l}\text { TPH (microhybrid } \\
\text { composite resin) }\end{array}$ & \multirow{3}{*}{ Increase } \\
\hline & & & & & & & & Adper Easy One & $\begin{array}{l}\text { Tetric Evoceram } \\
\text { (nanohybrid composite } \\
\text { resin) }\end{array}$ & \\
\hline & & & & & & & & Prime and Bond 2.1 & $\begin{array}{l}\text { TPH (microhybrid } \\
\text { composite resin) } \\
\text { Tetric Evoceram } \\
\text { (nanohybrid composite } \\
\text { resin) } \\
\end{array}$ & \\
\hline \multirow{2}{*}{$\begin{array}{l}\text { Ebrahimi-Chaharom et } \\
\text { al., (67) }\end{array}$} & \multirow[b]{2}{*}{$\begin{array}{l}\text { Before } \\
\text { bonding }\end{array}$} & \multirow[b]{2}{*}{ Solution } & \multirow[b]{2}{*}{5.25} & \multirow[b]{2}{*}{10} & \multirow{2}{*}{$\begin{array}{l}\text { Untreated } \\
\text { dentin }\end{array}$} & \multirow[b]{2}{*}{ Shear } & \multirow{2}{*}{$\begin{array}{l}\text { Human premolars, } \\
\text { coronal dentin }\end{array}$} & Clearfil $\mathrm{S}^{3}$ Bond & \multirow[b]{2}{*}{ Z100 (composite resin) } & \multirow[b]{2}{*}{ Decrease } \\
\hline & & & & & & & & Adaper Easy Bond & & \\
\hline Gönülol et al., (68) & $\begin{array}{l}\text { Before } \\
\text { bonding }\end{array}$ & Solution & 5.25 & 10 & $\begin{array}{c}\text { Dentin } \\
\text { irrigated } \\
\text { with distilled } \\
\text { water }\end{array}$ & Microtensile & $\begin{array}{l}\text { Human } 3^{\text {rd }} \text { molars, } \\
\text { coronal dentin }\end{array}$ & Clearfil SE Bond (2-step self-etch) & $\begin{array}{l}\text { Filtek Z550 (core build up } \\
\text { composite resisn) }\end{array}$ & Decrease \\
\hline Farina et al., (69) & $\begin{array}{l}\text { Before } \\
\text { bonding }\end{array}$ & Solution & 1 & 40 & $\begin{array}{l}\text { Untreated } \\
\text { dentin }\end{array}$ & Microtensile & $\begin{array}{l}\text { Human } 3^{\text {rd }} \text { molars, } \\
\text { coronal dentin }\end{array}$ & Clearfil SE Bond (self-etch) & Z250 (composite resin) & Decrease \\
\hline Nassar et al., (70) & $\begin{array}{l}\text { Before } \\
\text { bonding }\end{array}$ & Solution & 5 & 10 & $\begin{array}{l}\text { Dentin } \\
\text { irrigated } \\
\text { with } \\
\text { deionized } \\
\text { water }\end{array}$ & Shear & $\begin{array}{l}\text { Human } 3^{\text {rd }} \text { molars, } \\
\text { coronal dentin }\end{array}$ & $\begin{array}{l}\text { Ephiphany self-etch root canal } \\
\text { sealer }\end{array}$ & $\begin{array}{l}\text { Ephiphany (self-etch root } \\
\text { canal sealer) }\end{array}$ & Decrease \\
\hline \multirow{6}{*}{ Abo et al., (71) } & \multirow{6}{*}{$\begin{array}{l}\text { Before } \\
\text { bonding }\end{array}$} & & & & & & & $\begin{array}{l}\text { OptiBond FL (3-step etch \& rinse) } \\
\text { EL\#628 (2-step etch \& rinse) }\end{array}$ & & \\
\hline & & Solution & $0.5 \mathrm{v}$ & 60 & $\begin{array}{l}\text { Dentin } \\
\text { irrigated }\end{array}$ & Shear & Human molars, coronal & $\begin{array}{l}\text { OptiBond SOLO Plus (2-step self- } \\
\text { etch) }\end{array}$ & Filtek Supreme & Decrease \\
\hline & & & & & & & dentin & $\begin{array}{l}\text { Clearfil SE Bond (2-step self-etch) } \\
\text { AdheSE (2-step self-etch) }\end{array}$ & (composite resin) & \\
\hline & & & & & & & & iBond (1-step self-etch) & & \\
\hline & & & & & & & & $\begin{array}{l}\text { Adper Prompt L-Pop (1-step self- } \\
\text { etch) }\end{array}$ & & \\
\hline & & & & & & & & Xeno (1-step self-etch) & & \\
\hline Saber \& El-Askary (72) & $\begin{array}{l}\text { Before } \\
\text { bonding }\end{array}$ & Solution & 2.5 & - & $\begin{array}{c}\text { Untreated } \\
\text { dentin }\end{array}$ & Shear & $\begin{array}{l}\text { Human molars, coronal } \\
\text { dentin }\end{array}$ & $\begin{array}{l}\text { Clearfil S }{ }^{3} \text { bond (1-step self- } \\
\text { etching) }\end{array}$ & $\begin{array}{l}\mathrm{TPH}^{\mathrm{TM}} \text { Spectrum } \\
\text { (composite resin) }\end{array}$ & Decrease \\
\hline Kunawarote et al., (73) & $\begin{array}{l}\text { Before } \\
\text { bonding }\end{array}$ & Solution & 6 & $\frac{1 / 12}{1 / 4}$ & $\begin{array}{c}\text { Dentin } \\
\text { irrigated }\end{array}$ & Microtensile & $\begin{array}{l}\text { Human molars, coronal } \\
\text { dentin }\end{array}$ & $\begin{array}{l}\text { Clearfil SE Bond (2- step } \\
\text { self-etch) }\end{array}$ & $\begin{array}{l}\text { Clearfil AP-X (composite } \\
\text { resin) }\end{array}$ & No change \\
\hline & & & & $1 / 2$ & $\begin{array}{l}\text { with running } \\
\text { water }\end{array}$ & & & & & Decrease \\
\hline & & & & & & & & $\begin{array}{l}\text { Clearfil SA luting (self-adhesive } \\
\text { cement) }\end{array}$ & & \\
\hline & & & & $1 / 12$ & & & & Breeze (self-adhesive cement) & & \\
\hline Kambara et al., (74) & Before & Solution & 6 & & $\begin{array}{l}\text { Dentin } \\
\text { irrigated }\end{array}$ & Shear & Human molars, coronal & $\begin{array}{l}\text { Rely X Unicem clicker (self- } \\
\text { adhesive cement) }\end{array}$ & SUS-304 (stainless steel & Decrease \\
\hline & bonding & & & 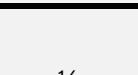 & $\begin{array}{l}\text { with running } \\
\text { water }\end{array}$ & & dentin & $\begin{array}{l}\text { Clearfil SA luting (self-adhesive } \\
\text { cement) }\end{array}$ & $\begin{array}{l}\text { rods that had been } \\
\text { sandblasted using } \\
50 \text { um alumina }\end{array}$ & \\
\hline
\end{tabular}




\begin{tabular}{|c|c|c|c|c|c|c|c|c|c|c|}
\hline & & & & & & & & $\begin{array}{l}\text { Rely X Unicem clicker (self- } \\
\text { adhesive cement) }\end{array}$ & & Increase \\
\hline $\begin{array}{l}\text { Ayad \& Garcia-Godoy } \\
\text { (75) }\end{array}$ & $\begin{array}{l}\text { Before } \\
\text { bonding }\end{array}$ & Solution & 5 & 1 & $\begin{array}{l}\text { Untreated } \\
\text { dentin }\end{array}$ & Push-out & $\begin{array}{l}\text { Human mandibular } 3^{\text {rd }} \\
\text { molars, coronal dentin }\end{array}$ & Epiphany primer & Epiphany sealer & Increase \\
\hline Kasraei et al., (76) & $\begin{array}{l}\text { Before } \\
\text { bonding }\end{array}$ & Solution & 2.5 & $1 / 4$ & $\begin{array}{l}\text { Untreated } \\
\text { dentin }\end{array}$ & Microtensile & $\begin{array}{l}\text { Human premolars, } \\
\text { coronal dentin }\end{array}$ & $\begin{array}{l}\text { Clearfil S3 (self-etch) } \\
\text { I-Bond (self-etch) }\end{array}$ & Z100 (composite resin) & No change \\
\hline Sasafuchi et al., (77) & $\begin{array}{l}\text { Before } \\
\text { bonding }\end{array}$ & Solution & 5 & 1 & $\begin{array}{l}\text { Untreated } \\
\text { dentin }\end{array}$ & Tensile & $\begin{array}{l}\text { Bovine incisors, coronal } \\
\text { dentin }\end{array}$ & $\begin{array}{l}\text { Super-Bond C\&B (resin cement) } \\
\text { Panavia F (resin cement) }\end{array}$ & Composite resin rods & $\begin{array}{l}\text { Decrease } \\
\text { No change }\end{array}$ \\
\hline $\begin{array}{l}\text { Prasansuttiporn et al., } \\
\text { (78) }\end{array}$ & $\begin{array}{l}\text { Before } \\
\text { bonding }\end{array}$ & Solution & 6 & $1 / 2$ & $\begin{array}{l}\text { Dentin } \\
\text { irrigated } \\
\text { with distilled } \\
\text { water }\end{array}$ & Microtensile & $\begin{array}{l}\text { Human } 3^{\text {rd }} \text { molars, } \\
\text { coronal dentin }\end{array}$ & $\begin{array}{l}\text { Clearfil Protect Bond (2-step self- } \\
\text { etch) }\end{array}$ & $\begin{array}{l}\text { Clearfil AP-X (composite } \\
\text { resin) }\end{array}$ & Decrease \\
\hline Vongphan et al., (79) & $\begin{array}{l}\text { Before } \\
\text { bonding }\end{array}$ & Solution & 5.25 & 10 & $\begin{array}{l}\text { Pulp } \\
\text { chamber } \\
\text { irrigated } \\
\text { with distilled } \\
\text { water }\end{array}$ & Microtensile & $\begin{array}{l}\text { Human } 3^{\text {rd }} \text { molars, pulp } \\
\text { chamber dentin (cavity in } \\
\text { pulp chamber was filled \& } \\
\text { sectioned vertically into } \\
\text { 0.8mm thick slabs that } \\
\text { were trimmed into } \\
\text { dumbbell shaped } \\
\text { specimens) }\end{array}$ & Single Bond (total-etch) & Z250 (composite resin) & Decrease \\
\hline \multirow{3}{*}{$\begin{array}{l}\text { Bhat Gorwish et al., } \\
\text { (80) }\end{array}$} & \multirow{3}{*}{$\begin{array}{l}\text { Before } \\
\text { bonding }\end{array}$} & \multirow{3}{*}{ Solution } & \multirow{3}{*}{3} & \multirow{3}{*}{1} & \multirow{3}{*}{$\begin{array}{l}\text { Pulp } \\
\text { chamber } \\
\text { irrigated } \\
\text { with distilled } \\
\text { water }\end{array}$} & \multirow{3}{*}{ Microtensile } & \multirow{3}{*}{$\begin{array}{l}\text { Human mandibular 3 } 3^{\text {rd }} \\
\text { molars, pulp chamber } \\
\text { dentin (cavity in pulp } \\
\text { chamber was filled then } \\
\text { sectioned) }\end{array}$} & Single Bond 2 & \multirow{3}{*}{$\begin{array}{l}\text { Solitaire (posterior } \\
\text { composite resin) }\end{array}$} & \multirow{3}{*}{ Decrease } \\
\hline & & & & & & & & Prime \& Bond NT & & \\
\hline & & & & & & & & Adhes SE & & \\
\hline \multirow{3}{*}{ Ozturk \& Ozer (81) } & \multirow{3}{*}{$\begin{array}{l}\text { Before } \\
\text { bonding }\end{array}$} & \multirow{3}{*}{ Solution } & \multirow{3}{*}{5} & \multirow{3}{*}{1} & \multirow{3}{*}{$\begin{array}{l}\text { Unirrigated } \\
\text { pulp } \\
\text { chamber }\end{array}$} & & Human mandibular $3^{\text {rd }}$ & Clearfil SE Bond & Clearfil AP-X & \\
\hline & & & & & & Microtensile & $\begin{array}{l}\text { molars, pulp chamber } \\
\text { dentin (cavity in pulp }\end{array}$ & Prompt-L Pop & Hytac & Decrease \\
\hline & & & & & & & $\begin{array}{l}\text { chamber was filled then } \\
\text { sectioned) }\end{array}$ & Schotbond Multipurpose Plus & Filtek Z250 & tocicos \\
\hline Santos et al., (82) & $\begin{array}{l}\text { Before } \\
\text { bonding }\end{array}$ & Solution & 5.25 & $\begin{array}{l}30 \text { (renewed } \\
\text { every } 3 \text { ) }\end{array}$ & $\begin{array}{c}\text { Pulp } \\
\text { chamber } \\
\text { irrigated } \\
\text { with } 0.9 \% \\
\text { saline }\end{array}$ & Tensile & $\begin{array}{l}\text { Bovine incisors, pulp } \\
\text { chamber dentin (cavity in } \\
\text { pulp chamber was filled) }\end{array}$ & Clearfil SE Bond (self-etch) & $\begin{array}{l}\text { Filtek Z250 (composite } \\
\text { resin) }\end{array}$ & Decrease \\
\hline Shretha et al., (83) & Before & Solution & 1.3 & 1 & $\begin{array}{c}\text { Dentin } \\
\text { irrigated } \\
\text { with distilled }\end{array}$ & Micropush- & $\begin{array}{l}\text { Human single rooted } \\
\text { teeth, simulated (vertically } \\
\text { oriented truncated) canals }\end{array}$ & RealSeal SE (self-etching & RealSeal SE (self- & Increase \\
\hline & bonding & & 5.2 & & water & out & $\begin{array}{l}\text { were prepared in middle } \\
\text { of radicular dentin in } \\
\text { longitudinal slices cut } \\
\text { below CEJ and filled }\end{array}$ & adhesive sealer) & etching adhesive sealer) & \\
\hline Morris et al., (84) & $\begin{array}{l}\text { Before } \\
\text { bonding }\end{array}$ & Solution & 5 & $15-20$ & $\begin{array}{l}\text { Root canals } \\
\text { irrigated } \\
\text { with } 0.9 \% \\
\text { saline }\end{array}$ & Tensile & $\begin{array}{l}\text { Human maxillary incisors } \\
\text { and mixed canines, root } \\
\text { canal dentin (after filling } \\
\text { root canal, they were } \\
\text { sectioned into } 1 \mathrm{~mm} \text { thick } \\
\text { slabs from CEJ to apex) }\end{array}$ & C\&B Metabond & C\&B Metabond & Decrease \\
\hline Manimaran et al., (85) & $\begin{array}{l}\text { Before } \\
\text { bonding }\end{array}$ & Solution & 5.25 & $15-20$ & $\begin{array}{l}\text { Root canals } \\
\text { irrigated } \\
\text { using } 0.9 \% \\
\text { saline } \\
\end{array}$ & Microtensile & $\begin{array}{l}\text { Human single rooted } \\
\text { teeth, root canal } \\
\text { obturated with root a } \\
\text { canal sealer } \\
\end{array}$ & Adper ${ }^{T M}$ ( self-etch) & RelyX ${ }^{\mathrm{TM}}$ (resin cement) & Decrease \\
\hline Erdemire et al., (21) & $\begin{array}{l}\text { Before } \\
\text { bonding }\end{array}$ & Solution & 5 & 1 & $\begin{array}{l}\text { Root canal } \\
\text { irrigated } \\
\text { with water }\end{array}$ & Microtensile & $\begin{array}{l}\text { Human single rooted } \\
\text { teeth, root canal dentin } \\
\text { (after filling root canal, } \\
\text { they were sectioned into }\end{array}$ & C\&B Metabond & C\&B Metabond & Decrease \\
\hline
\end{tabular}




\begin{tabular}{|c|c|c|c|c|c|c|c|c|c|c|}
\hline & & & & & & & $\begin{array}{l}1 \mathrm{~mm} \text { thick slabs from } \\
\text { CEJ to apex) }\end{array}$ & & & \\
\hline Gu et al., (43) & $\begin{array}{l}\text { Before } \\
\text { bonding }\end{array}$ & Solution & 5.25 & 1 & $\begin{array}{l}\text { Root } \\
\text { canals } \\
\text { irrigated } \\
\text { using } 0.9 \% \\
\text { saline }\end{array}$ & Push-out & $\begin{array}{l}\text { Human single rooted } \\
\text { teeth, root canal } \\
\text { obturated with gutta } \\
\text { percha and AH Plus, } \\
\text { then a post space was } \\
\text { prepared and filled with a } \\
\text { resin cement }\end{array}$ & Panavia F resin cement & Panavia F (resin cement) & Decrease \\
\hline \multirow{3}{*}{ Ari et al., (86) } & \multirow{3}{*}{$\begin{array}{l}\text { Before } \\
\text { bonding }\end{array}$} & \multirow{3}{*}{ Solution } & \multirow{3}{*}{5} & \multirow{3}{*}{5} & \multirow{3}{*}{$\begin{array}{l}\text { Root canal } \\
\text { irrigated } \\
\text { with water }\end{array}$} & \multirow{3}{*}{ Microtensile } & \multirow{3}{*}{$\begin{array}{l}\text { Human single rooted } \\
\text { tooth, root canal dentin } \\
\text { (after filling root canal, } \\
\text { they were sectioned into } \\
1 \mathrm{~mm} \text { thick slabs from } \\
\text { CEJ to apex) }\end{array}$} & C\&B Metabond & C\&B Metabond & \multirow{2}{*}{ Decrease } \\
\hline & & & & & & & & $\begin{array}{l}\text { PanaviaF } \\
\text { Variolink II }\end{array}$ & $\begin{array}{l}\text { PanaviaF } \\
\text { Variolink II }\end{array}$ & \\
\hline & & & & & & & & Rely-X & Rely-X & No change \\
\hline \multirow[t]{2}{*}{ Stelzer et al., (87) } & \multirow{2}{*}{$\begin{array}{l}\text { Before } \\
\text { bonding }\end{array}$} & \multirow[t]{2}{*}{ Solution } & \multirow[t]{2}{*}{$\overline{3}$} & \multirow[t]{2}{*}{$\overline{4}$} & \multirow{2}{*}{$\begin{array}{c}\text { Root canal } \\
\text { irrigated } \\
\text { with } 0.9 \% \\
\text { saline } \\
\end{array}$} & \multirow[t]{2}{*}{ Push-out } & \multirow{2}{*}{$\begin{array}{l}\text { Human teeth, root canal } \\
\text { obturated with a filling } \\
\text { material and a sealer }\end{array}$} & AH Plus (sealer) & Gutta percha & No change \\
\hline & & & & & & & & RealSealSE (sealer) & Resilon & Decrease \\
\hline \multirow[b]{3}{*}{$\begin{array}{l}\text { Haragushiku et al., } \\
\text { (88) }\end{array}$} & \multirow[b]{3}{*}{$\begin{array}{l}\text { Before } \\
\text { bonding }\end{array}$} & \multirow[b]{3}{*}{ Solution } & \multirow[b]{3}{*}{1} & \multirow[b]{3}{*}{30} & \multirow{3}{*}{$\begin{array}{l}\text { Root canal } \\
\text { irrigated } \\
\text { with distilled } \\
\quad \text { water }\end{array}$} & \multirow[b]{3}{*}{ Push-out } & \multirow{3}{*}{$\begin{array}{l}\text { Human maxillary canines, } \\
\text { root canal obturated with } \\
\text { a root canal sealer, then } \\
\text { a post space was } \\
\text { prepared and filled with a } \\
\text { resin cement }\end{array}$} & - & Apexit Plus & \multirow[b]{3}{*}{ No change } \\
\hline & & & & & & & & & AH Plus & \\
\hline & & & & & & & & $\begin{array}{l}\text { Epiphany-self etching } \text { primer } \\
\text { Epiphany-self etching primer }\end{array}$ & $\begin{array}{l}\text { Epiphany-auto mixed } \\
\text { Epiphany-hand mixed }\end{array}$ & \\
\hline \multirow{2}{*}{ Ishizuka et al., (89) } & \multirow[b]{2}{*}{$\begin{array}{l}\text { Before } \\
\text { bonding }\end{array}$} & \multirow{2}{*}{ Solution } & \multirow{2}{*}{$6 \mathrm{v} / \mathrm{v}$} & \multirow{2}{*}{$1,5 \& 10$} & & \multirow{2}{*}{$\begin{array}{l}\text { Push -out } \\
\text { shear }\end{array}$} & \multirow{2}{*}{$\begin{array}{l}\text { Bovine mandibular } 1^{\text {st }} \& \\
2^{\text {nd }} \text { incisors, root canal } \\
\text { dentin } \\
\text { (after filling root canal } \\
\text { with gutta-percha, a } \\
\text { truncated cone cavity of } 4 \\
\text { mm diameter \& } 2.5 \mathrm{~mm} \\
\text { height within coronal part } \\
\text { of the root was prepared. } \\
\text { Cavity was then filled and } \\
\text { sectioned into } 1 \mathrm{~mm} \text { thick } \\
\text { slabs) }\end{array}$} & $\begin{array}{l}\text { Clearfil Mega Bond (self-etch } \\
\text { primer) }\end{array}$ & \multirow{2}{*}{$\begin{array}{l}\text { Clearfil AP-X (composite } \\
\text { resin) }\end{array}$} & Decrease \\
\hline & & & & & - & & & Single Bond (total-etch) & & No change \\
\hline \multirow[t]{2}{*}{ Rocha et al., (42) } & Before & Solution & 2.5 & 3 & Root canal & Push -out & Bovine central incisore, & Epiphany (sealer) & Resilon & Increase \\
\hline & bonding & & & & $\begin{array}{l}\text { irrigated } \\
\text { with } 0.9 \% \\
\text { saline }\end{array}$ & & root canal obturated & AH Plus (sealer) & Gutta percha & Decrease \\
\hline Weston et al., (31) & $\begin{array}{l}\text { Before } \\
\text { bonding }\end{array}$ & Solution & 5.25 & $15-20$ & $\begin{array}{l}\text { Root canals } \\
\text { irrigated } \\
\text { with } 0.9 \% \\
\text { saline }\end{array}$ & Tensile & $\begin{array}{l}\text { Human maxillary incisors } \\
\text { and mixed canines, root } \\
\text { canal obturated with C\&B } \\
\text { Metabond }\end{array}$ & C\&B Metabond & C\&B Metabond & Decrease \\
\hline & & & $-5.25(10 \mathrm{ml}$ & & Root canal & & $\begin{array}{l}\text { Human mandibular } \\
\text { premolars teeth, root }\end{array}$ & $\begin{array}{l}\text { Panavia F2 (self-etch resin } \\
\text { cement) }\end{array}$ & & \\
\hline Bournziniat et al., (90) & $\begin{array}{l}\text { Before } \\
\text { bonding }\end{array}$ & Solution & $\begin{array}{l}\text { during root canal } \\
\text { shaping) }\end{array}$ & 1 & $\begin{array}{l}\text { irrigated } \\
\text { with normal } \\
\text { saline }\end{array}$ & Pull-out & $\begin{array}{l}\text { canal obturated with gutta } \\
\text { percha and AH- } 26 \text { sealer, } \\
\text { then a post space was } \\
\text { prepared and filled with a } \\
\text { post. }\end{array}$ & $\begin{array}{l}\text { Embrace (self-adhesive resin } \\
\text { cement) }\end{array}$ & $\begin{array}{l}\text { White Post DC3 (fiber } \\
\text { reinforced composite } \\
\text { posts) }\end{array}$ & Decrease \\
\hline Lacerda et al., (91) & $\begin{array}{l}\text { Before } \\
\text { bonding }\end{array}$ & Solution & 2.5 & - & $\begin{array}{l}\text { Root canal } \\
\text { irrigated } \\
\text { with normal } \\
\text { saline }\end{array}$ & Push-out & $\begin{array}{l}\text { Bovine incisors, root } \\
\text { canal obturated with gutta } \\
\text { percha and calcium } \\
\text { hydroxide sealer (Sealer } \\
\text { 26), then a post space }\end{array}$ & $\begin{array}{l}\text { Futurabond DC (self-etch dual- } \\
\text { cure adhesive) + Bifix QM (epoxy- } \\
\text { based dual-cure resin) }\end{array}$ & Glass fiber posts & Decrease \\
\hline
\end{tabular}




\begin{tabular}{|c|c|c|c|c|c|c|c|c|c|c|}
\hline & & & & & & & $\begin{array}{l}\text { was prepared and filled } \\
\text { with a post. }\end{array}$ & & & \\
\hline \multirow[t]{2}{*}{ Khoroushi et al., (92) } & \multirow{2}{*}{$\begin{array}{l}\text { Before } \\
\text { bonding }\end{array}$} & \multirow[t]{2}{*}{ Solution } & $\begin{array}{l}-2.5 \text { (during root } \\
\text { canal shaping) }\end{array}$ & 1 & \multirow{2}{*}{$\begin{array}{c}\text { Root canal } \\
\text { irrigated } \\
\text { with normal } \\
\text { saline }\end{array}$} & \multirow[t]{2}{*}{ Pull-out } & \multirow{2}{*}{$\begin{array}{l}\text { Human single rooted } \\
\text { teeth, root canal } \\
\text { obturated with gutta } \\
\text { percha and AH26 sealer, } \\
\text { then a post space was } \\
\text { prepared and filled with a } \\
\text { silica-coated and Rocatic } \\
\text { system (ESPE Sil)- } \\
\text { silanized post. }\end{array}$} & \multirow[t]{2}{*}{$\begin{array}{l}\text { Ceramic Bond + Bifix SE (1-step } \\
\text { self-etch cement) }\end{array}$} & \multirow[t]{2}{*}{$\begin{array}{l}\text { Stainless steel spreaders } \\
\# 55 \text { with handles }\end{array}$} & \multirow[t]{2}{*}{ Decrease } \\
\hline & & & $\begin{array}{c}-2.5 \text { (after } \\
\text { preparation of } \\
\text { post space) }\end{array}$ & 2 & & & & & & \\
\hline \multirow[t]{2}{*}{ Arisu et al., (93) } & \multirow{2}{*}{$\begin{array}{l}\text { Before } \\
\text { bonding }\end{array}$} & \multirow[t]{2}{*}{ Solution } & $\begin{array}{l}-2.25 \text { (during } \\
\text { root canal } \\
\text { shaping) }\end{array}$ & - & \multirow{2}{*}{$\begin{array}{c}\text { Root canal } \\
\text { irrigated } \\
\text { with distilled } \\
\quad \text { water }\end{array}$} & \multirow{2}{*}{ Push-out } & \multirow{2}{*}{$\begin{array}{l}\text { Human mandibular } \\
\text { premolars, root canal } \\
\text { obturated with gutta } \\
\text { percha and AH26 sealer, } \\
\text { then a post space was } \\
\text { prepared and filled with a } \\
\text { post }\end{array}$} & \multirow[t]{2}{*}{ Panavia F 2.0 (resin cement) } & \multirow{2}{*}{$\begin{array}{l}\text { Mirafit White (glass fiber } \\
\text { posts) }\end{array}$} & \multirow[t]{2}{*}{ Decrease } \\
\hline & & & $\begin{array}{l}-2.25(5 \mathrm{ml} \text { after } \\
\text { preparation of } \\
\text { post space })\end{array}$ & 1 & & & & & & \\
\hline \multirow[b]{2}{*}{$\begin{array}{l}\text { Alkhudhairy \& Bin- } \\
\text { Shuwaish (94) }\end{array}$} & \multirow[b]{2}{*}{$\begin{array}{l}\text { Before } \\
\text { bonding }\end{array}$} & \multirow[b]{2}{*}{ Solution } & 2.5 & - & \multirow{2}{*}{$\begin{array}{l}\text { Root canal } \\
\text { irrigated } \\
\text { with } \mathrm{NaCl}\end{array}$} & \multirow[b]{2}{*}{ Push-out } & \multirow{2}{*}{$\begin{array}{l}\text { Human incisors, root } \\
\text { canal obturated with gutta } \\
\text { percha with AH-26 sealer, } \\
\text { then a post space was } \\
\text { prepared and filled with } \\
\text { post }\end{array}$} & $\begin{array}{l}\text { MultiCore Flow (core build-up) } \\
\text { RelyX-UniCem (self-adhesive resin } \\
\text { cement) }\end{array}$ & \multirow[t]{2}{*}{ No.3 RelyX (fiber post) } & $\begin{array}{l}\text { Increase }+++ \\
\text { Increase }++\end{array}$ \\
\hline & & & 5.25 & - & & & & $\begin{array}{l}\text { MultiCore Flow (core build-up) } \\
\text { RelyX-UniCem (self-adhesive resin } \\
\text { cement) }\end{array}$ & & $\begin{array}{l}\text { Increase + } \\
\text { Increase + }\end{array}$ \\
\hline \multirow[b]{2}{*}{$\begin{array}{l}\text { Faria-e-Silva et al., } \\
\text { (95) }\end{array}$} & \multirow[b]{2}{*}{$\begin{array}{l}\text { Before } \\
\text { bonding }\end{array}$} & \multirow[b]{2}{*}{ Solution } & $\begin{array}{l}-2.5 \text { (during root } \\
\text { canal shaping) }\end{array}$ & & \multirow{2}{*}{$\begin{array}{l}\text { Root canals } \\
\text { received no } \\
\text { irrigation }\end{array}$} & \multirow[b]{2}{*}{ Push-out } & \multirow{2}{*}{$\begin{array}{l}\text { Bovine incisors, root } \\
\text { canal obturated with gutta } \\
\text { percha and resin sealer } \\
\text { (Sealer-26), then a post } \\
\text { space was prepared and } \\
\text { filled with an etched ( } 24 \% \\
\mathrm{H} 2 \mathrm{O} 2 \text { for } 10 \mathrm{~min} \text { ) \& } \\
\text { silanated post. }\end{array}$} & $\begin{array}{l}\text { BisCem (self-adhesive resin } \\
\text { cement) }\end{array}$ & \multirow{2}{*}{$\begin{array}{l}\text { FRC post (glass fiber } \\
\text { reinforced epoxy posts) }\end{array}$} & \multirow{2}{*}{ Increase } \\
\hline & & & $\begin{array}{l}-5 \text { (after } \\
\text { preparation of } \\
\text { post space) }\end{array}$ & 1 & & & & $\begin{array}{l}\text { RelyX Unicem clicker (self- } \\
\text { adhesive resin cement) }\end{array}$ & & \\
\hline & & & $\begin{array}{l}-2.5(25 \mathrm{ml} \\
\text { during root canal }\end{array}$ & & & & & $\begin{array}{l}\text { Schotbond Multipurpose + RelyX } \\
\text { ARC (resin cement) }\end{array}$ & & \\
\hline & & & shaping) & & $\begin{array}{l}\text { Root canal } \\
\text { irrigated }\end{array}$ & & $\begin{array}{l}\text { Bovine mandibular } \\
\text { incisors, root canal }\end{array}$ & $\begin{array}{l}\text { ED Primer + Panavia F (resin } \\
\text { cement) }\end{array}$ & & No change \\
\hline Bupnot of (6) & & Solution & & - & with saline & Push-out & obturated with gutta & RelyX U100 (resin cement) & & \\
\hline Bueno et al., (96) & $\begin{array}{l}\text { Before } \\
\text { bonding }\end{array}$ & Solution & $\begin{array}{l}-5.25 \text { (during } \\
\text { root canal }\end{array}$ & & & & $\begin{array}{l}\text { sealer, then a post space } \\
\text { was prepared and filled }\end{array}$ & $\begin{array}{l}\text { Schotbond Multipurpose + RelyX } \\
\text { ARC (resin cement) }\end{array}$ & $\begin{array}{l}\text { Reforpost No. } 3 \text { (glass } \\
\text { fiber posts) }\end{array}$ & \\
\hline & & & shaping) & & & & $\begin{array}{l}\text { was prepared and tilled } \\
\text { with an etched ( } 37 \% \\
\text { H3PO4 for } 15 \mathrm{~s}) \&\end{array}$ & $\begin{array}{l}\text { ED Primer + Panavia F (resin } \\
\text { cement) }\end{array}$ & & \\
\hline & & & & & & & silanated pos & RelyX U100 (resin cement) & & Decrease \\
\hline & & & $\begin{array}{l}-1(1 \mathrm{ml} \\
\text { during root canal } \\
\text { shaping) }\end{array}$ & - & & & & AdheSE (self-etch adhesive) & $\begin{array}{l}\text { Post FRC Postec and } \\
\text { MultiCore Flow as core } \\
\text { material }\end{array}$ & No change \\
\hline Bitter et al., (97) & Before & Solution & $\begin{array}{l}-1(5 \mathrm{ml} \text { after } \\
\text { preparation of }\end{array}$ & 1 & $\begin{array}{l}\text { Root canals } \\
\text { irrigated }\end{array}$ & Push-out & $\begin{array}{l}\text { Human maxillary central } \\
\text { incisors, root canal }\end{array}$ & $\begin{array}{l}\text { XP Bond (etch \& rinse) \& self-cure } \\
\text { activator }\end{array}$ & $\begin{array}{l}\text { Post X Post and the core } \\
\text { material Core X Flow }\end{array}$ & Increase \\
\hline & bonding & & post space) & & $\begin{array}{l}\text { with distilled } \\
\text { water }\end{array}$ & & $\begin{array}{l}\text { obturated with gutta } \\
\text { percha and AH Plus, }\end{array}$ & $\begin{array}{l}\text { SmartCem2 (self-adhesive resin } \\
\text { cement) }\end{array}$ & Post X Post & \\
\hline & & & $\begin{array}{l}-1(1 \mathrm{ml} \\
\text { during root canal } \\
\text { shaping) }\end{array}$ & & & & $\begin{array}{l}\text { then a post space was } \\
\text { prepared and filled with a } \\
\text { post }\end{array}$ & AdheSE (self-etch) & $\begin{array}{l}\text { Post FRC Postec and } \\
\text { MultiCore Flow as core } \\
\text { material }\end{array}$ & No change \\
\hline & & & $\begin{array}{l}-5.25(5 \mathrm{ml} \text { after } \\
\text { preparation of }\end{array}$ & 1 & & & & $\begin{array}{l}\text { XP Bond (etch \& rinse) \& self-cure } \\
\text { activator }\end{array}$ & $\begin{array}{l}\text { Post X Post and the core } \\
\text { material Core X Flow }\end{array}$ & 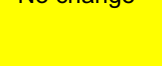 \\
\hline & & & post space) & & & & & $\begin{array}{l}\text { SmartCem2 (self-adhesive resin } \\
\text { cement) }\end{array}$ & Post X Post & \\
\hline
\end{tabular}




\begin{tabular}{|c|c|c|c|c|c|c|c|c|c|c|}
\hline Ertas et al., (98) & $\begin{array}{l}\text { Before } \\
\text { bonding }\end{array}$ & Solution & $\begin{array}{l}-2.5(1 \mathrm{ml} \\
\text { during root canal } \\
\text { shaping }) \\
-5.25(5 \mathrm{ml} \text { after } \\
\text { preparation of } \\
\text { post space })\end{array}$ & 5 & $\begin{array}{l}\text { Root canals } \\
\text { irrigated } \\
\text { with } 0.9 \% \\
\text { saline }\end{array}$ & Push-out & $\begin{array}{l}\text { Human single rooted } \\
\text { teeth, root canal } \\
\text { obturated with gutta } \\
\text { percha and AH Plus, } \\
\text { then a post space was } \\
\text { prepared and filled with a } \\
\text { post }\end{array}$ & Bifix SE (dual-cure resin cement) & Fiber posts & Increase \\
\hline \multirow{3}{*}{ Pelegrine et al., (99) } & \multirow{3}{*}{$\begin{array}{l}\text { Before } \\
\text { bonding }\end{array}$} & \multirow{3}{*}{ Solution } & $\begin{array}{l}-1(20 \mathrm{ml} \text { during } \\
\text { root canal } \\
\text { shaping) }\end{array}$ & \multirow[t]{3}{*}{-} & \multirow{3}{*}{$\begin{array}{l}\text { Root canals } \\
\text { irrigated } \\
\text { with } 0.9 \% \\
\text { saline }\end{array}$} & \multirow{3}{*}{ Tensile } & \multirow{3}{*}{$\begin{array}{l}\text { Bovin teeth, root canal } \\
\text { obturated with M gutta } \\
\text { perch and AH Plus } \\
\text { sealer, then a post space } \\
\text { was prepared and filled } \\
\text { with a H3PO4 etched and } \\
\text { silanized (using Clearfil } \\
\text { Porcelain } \\
\text { Bond Activator \& Clearfil } \\
\text { SE Primer) post }\end{array}$} & \multirow{3}{*}{$\begin{array}{l}\text { Clearfil SE Bond (2-step self-etch) } \\
\text { + RelyX ARC (resin cement) }\end{array}$} & \multirow{3}{*}{ Glass fiber post } & \multirow{3}{*}{ No change } \\
\hline & & & $\begin{array}{l}-2.5(20 \mathrm{ml} \\
\text { during root canal } \\
\text { shaping })\end{array}$ & & & & & & & \\
\hline & & & $\begin{array}{l}-5.25(20 \mathrm{ml} \\
\text { during root canal } \\
\text { shaping })\end{array}$ & & & & & & & \\
\hline $\begin{array}{l}\text { Haragushiku et al., } \\
(100)\end{array}$ & $\begin{array}{l}\text { Before } \\
\text { bonding }\end{array}$ & Solution & 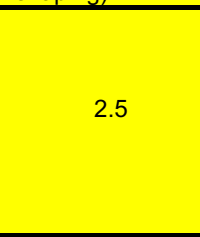 & 1 & $\begin{array}{l}\text { Root canals } \\
\text { irrigated } \\
\text { with distilled } \\
\text { water }\end{array}$ & Push-out & $\begin{array}{l}\text { Human maxillary canines, } \\
\text { root canal obturated with } \\
\text { gutta percha, accessory } \\
\text { MF cones and AH Plus } \\
\text { sealer, then a post space } \\
\text { was prepared and filled } \\
\text { with a silanized (Prosil) - } \\
\text { post. }\end{array}$ & $\begin{array}{l}\text { Ambar FGM (2-step etch \& rinse) } \\
+ \\
\text { AllCem (dual-cure resin-based } \\
\text { cement) }\end{array}$ & $\begin{array}{l}\text { WhitePost DC2 (glass- } \\
\text { fiber post) }\end{array}$ & No change \\
\hline Kaif and Raj (101) & $\begin{array}{l}\text { Before } \\
\text { bonding }\end{array}$ & Solution & $\begin{array}{l}-5.25(5 \mathrm{ml} \\
\text { during root canal } \\
\text { shaping) } \\
-5.25 \text { (after } \\
\text { preparation of } \\
\text { post space) }\end{array}$ & - & $\begin{array}{l}\text { Root canals } \\
\text { irrigated } \\
\text { with distilled } \\
\text { water }\end{array}$ & Push out & $\begin{array}{l}\text { Human single rooted } \\
\text { teeth, root canal } \\
\text { obturated with gutta } \\
\text { percha and AH-Plus } \\
\text { sealer, then a post space } \\
\text { was prepared and filled } \\
\text { with a H3PO4 etched } \\
\text { post. }\end{array}$ & $\begin{array}{l}\text { Adaper Single Bond } 2+ \\
\text { RelyX ARC }{ }^{\ominus} \text { resin cement }\end{array}$ & $\begin{array}{l}\text { FiberKor }^{\circledR} \text { post (glass } \\
\text { fiber posts) }\end{array}$ & No change \\
\hline \multirow[t]{2}{*}{ Saraiva et al., (44) } & \multirow[b]{2}{*}{$\begin{array}{l}\text { Before } \\
\text { bonding }\end{array}$} & \multirow[b]{2}{*}{ Solution } & \multirow{2}{*}{$\begin{array}{l}-2 \text { (during root } \\
\text { canal shaping) } \\
-5.25 \text { (after } \\
\text { preparation of } \\
\text { post space) }\end{array}$} & \multirow{2}{*}{$\begin{array}{l}- \\
\end{array}$} & \multirow[b]{2}{*}{$\begin{array}{l}\text { Root canals } \\
\text { received no } \\
\text { irrigation }\end{array}$} & \multirow[b]{2}{*}{ Push-out } & \multirow{2}{*}{$\begin{array}{l}\text { Human incisors, root } \\
\text { canal obturated with gutta } \\
\text { percha, then a post space } \\
\text { was prepared and filled } \\
\text { with a silanated post }\end{array}$} & $\begin{array}{l}\text { Excite Dual-self-cure (2-step etch } \\
\& \text { rinse) }\end{array}$ & \multirow[b]{2}{*}{$\begin{array}{l}\text { FRC Postec } \circledast \text { Plus (fiber } \\
\text { posts) }\end{array}$} & \multirow[b]{2}{*}{ No change } \\
\hline & & & & & & & & $\begin{array}{l}\text { Variolink II (dual-cure resin } \\
\text { cement) }\end{array}$ & & \\
\hline Cecchin et al., (102) & $\begin{array}{l}\text { After etching } \\
\text { with } 37 \% \\
\text { H3PO4 for } \\
15 \text { s }\end{array}$ & Solution & 5.25 & 5 & $\begin{array}{l}\text { Root canals } \\
\text { irrigated } \\
\text { with } 0.9 \% \\
\text { saline }\end{array}$ & Push-out & $\begin{array}{l}\text { Bovine incisors, root } \\
\text { canal obturated with an } \\
\text { etched }(\mathrm{H} 3 \mathrm{PO} 4) \text { and } \\
\text { resin covered post }\end{array}$ & $\begin{array}{l}\text { Adaper Schotchbond Mutipurpose } \\
\text { (total etch) + Rely X ARC (dual- } \\
\text { cure resin cement) }\end{array}$ & $\begin{array}{l}\text { Fiberglass post relined } \\
\text { with Z250 composite } \\
\text { resin }\end{array}$ & No change \\
\hline \multirow[t]{2}{*}{ Inoue et al., (103) } & $\begin{array}{l}\text { After etching } \\
\text { with } \mathrm{H} 3 \mathrm{PO} 4 \\
\text { semi-gel for } \\
15 \mathrm{~s}\end{array}$ & Gel & - & 1 & $\begin{array}{l}\text { Root canals } \\
\text { received no } \\
\text { irrigation }\end{array}$ & Microtensile & $\begin{array}{l}\text { Human molars, root } \\
\text { canal obturated with } \\
\text { gutta perch and zinc } \\
\text { oxide eugnol sealer, then } \\
\text { a post space was } \\
\text { prepared and filled with } \\
\text { an etched (H3PO4) and } \\
\text { silanized (porcelain } \\
\text { activator + Primer A \& B } \\
\text { of Clerfil Liner Bond II) } \\
\text { indirect resin core } \\
\end{array}$ & ED Primer + Panavia FluroCement & $\begin{array}{l}\text { Indirect Clearfil DC resin } \\
\text { core-build up }\end{array}$ & Increase \\
\hline & & & & & & & $\begin{array}{l}\text { Human maxillary central } \\
\text { incisors, root canal }\end{array}$ & $\begin{array}{l}\text { One Step Plus (lightly filled resin- } \\
\text { based adhesive) + DUO LINK }\end{array}$ & & \\
\hline
\end{tabular}




\begin{tabular}{|c|c|c|c|c|c|c|c|c|c|c|}
\hline \multirow[t]{2}{*}{ Mao et al., (104) } & \multirow{2}{*}{$\begin{array}{l}\text { After etching } \\
\text { with } 32 \% \\
\text { H3PO4 semi- } \\
\text { gel for } 15 \text { s }\end{array}$} & \multirow[t]{2}{*}{ Solution } & \multirow[t]{2}{*}{10} & \multirow[t]{2}{*}{1} & \multirow{2}{*}{$\begin{array}{l}\text { Root canals } \\
\text { irrigated } \\
\text { with } 0.9 \% \\
\text { saline }\end{array}$} & \multirow[t]{2}{*}{ Push-out } & \multirow{2}{*}{$\begin{array}{l}\text { obturated with gutta } \\
\text { perch and AH } 26 \text { sealer, } \\
\text { then a post space was } \\
\text { prepared and filled with a } \\
\text { post }\end{array}$} & $\begin{array}{l}\text { (heavily filled dual-cure resin } \\
\text { composite cements) }\end{array}$ & \multirow{2}{*}{$\begin{array}{l}\text { Quartz fiber-reinforced } \\
\text { double tapered posts }\end{array}$} & \multirow[t]{2}{*}{ Increase } \\
\hline & & & & & & & & $\begin{array}{l}\text { One Step Plus (lightly filled resin- } \\
\text { based adhesive) LuxaCore } \\
\text { (heavily filled dual-cure resin } \\
\text { composite cements) }\end{array}$ & & \\
\hline \multirow{4}{*}{ Varela et al., (105) } & \multirow{4}{*}{$\begin{array}{l}\text { After etching } \\
\text { with } 37 \% \\
\text { ortho-H3PO4 } \\
\text { for } 60 \text { s }\end{array}$} & \multirow{4}{*}{ Solution } & \multirow{2}{*}{$\begin{array}{l}-10 \text { (during root } \\
\text { canal shaping) }\end{array}$} & \multirow{2}{*}{-} & \multirow{4}{*}{$\begin{array}{l}\text { Root canals } \\
\text { received no } \\
\text { irrigation }\end{array}$} & \multirow{4}{*}{ Tensile } & \multirow{4}{*}{$\begin{array}{l}\text { Human single rooted } \\
\text { teeth, root canal } \\
\text { obturated with gutta } \\
\text { percha and TopSeal } \\
\text { sealer, then a post space } \\
\text { was prepared and filled } \\
\text { with a post }\end{array}$} & Panavia 21EX cement & \multirow{4}{*}{ Posts } & \multirow[t]{2}{*}{ No change } \\
\hline & & & & & & & & Dual Cement & & \\
\hline & & & \multirow{2}{*}{$\begin{array}{l}-10 \text { (after } \\
\text { preparation of } \\
\text { post space) }\end{array}$} & \multirow[t]{2}{*}{1} & & & & $\begin{array}{l}\text { Panavia } 21 \text { Ex cement with ED } \\
\text { Primer dentin adhesive }\end{array}$ & & \multirow[t]{2}{*}{ Increase } \\
\hline & & & & & & & & $\begin{array}{l}\text { Dual Cement with ED Primer } \\
\text { dentin } \\
\text { adhesive }\end{array}$ & & \\
\hline \multirow[b]{2}{*}{ Furuse et al., (106) } & After etching & \multirow[b]{2}{*}{ Solution } & \multirow[b]{2}{*}{$5.25 \mathrm{v} / \mathrm{v}$} & \multirow[b]{2}{*}{10} & \multirow{2}{*}{$\begin{array}{l}\text { Root canals } \\
\text { irrigated } \\
\text { with saline } \\
\text { solution }\end{array}$} & \multirow[b]{2}{*}{ Push-out } & \multirow{2}{*}{$\begin{array}{l}\text { Bovine incisors, obturated } \\
\text { with gutta percha and } \\
\text { calcium hydroxide sealer } \\
\text { (Sealer 26), root canal } \\
\text { openings were sealed } \\
\text { with glass ionomer, then } \\
\text { a post space was } \\
\text { prepared and filled with a } \\
\text { post. }\end{array}$} & $\begin{array}{l}\text { Schotbond Multipurpose (3-steps } \\
\text { etch \& rinse) + RelyX ARC (dual- } \\
\text { cure resin cement) }\end{array}$ & \multirow[b]{2}{*}{ Fiber reinforced posts } & No change \\
\hline & $\begin{array}{l}\text { Before } \\
\text { bonding }\end{array}$ & & & & & & & $\begin{array}{l}\text { Xeno III (1-step self-etch) + RelyX } \\
\text { ARC (dual-cure resin cement) }\end{array}$ & & Decrease \\
\hline \multirow{3}{*}{ da Cunba et al., (107) } & $\begin{array}{l}\text { Before } \\
\text { bonding }\end{array}$ & \multirow{3}{*}{ Solution } & \multirow{3}{*}{$5.25 \mathrm{v} / \mathrm{v}$} & \multirow{3}{*}{10} & \multirow{3}{*}{$\begin{array}{l}\text { Root canal } \\
\text { irrigated } \\
\text { with } 0.9 \% \\
\text { saline }\end{array}$} & \multirow{3}{*}{ Push-out } & \multirow{3}{*}{$\begin{array}{l}\text { Bovin incisors, root canal } \\
\text { obturated with gutta } \\
\text { percha and CaOH sealer, } \\
\text { root canal opening filled } \\
\text { with glass ionoomer } \\
\text { cement, then a post } \\
\text { space was prepared and } \\
\text { filled with post }\end{array}$} & $\begin{array}{l}\text { Rely X U100 (self-adhesive } \\
\text { cement) }\end{array}$ & & \\
\hline & After etching & & & & & & & $\begin{array}{l}\text { Rely X ARC (dual-cure cement) } \\
\text { with Single Bond } 2 \text { ( } 2 \text {-step etch \& } \\
\text { rinse) }\end{array}$ & Excato \#3 (fiber posts) & Decrease \\
\hline & $\begin{array}{l}\text { Before } \\
\text { bonding }\end{array}$ & & & & & & & $\begin{array}{l}\text { Rely X ARC (dual-cure cement) } \\
\text { with Clearfil SE Bond (2-step self- } \\
\text { etch) }\end{array}$ & & \\
\hline
\end{tabular}

$\mathrm{NaOCl}$ applied after etching ( $1^{\text {st }}$ step of bonding) to coronal dentin

$\mathrm{NaOCl}$ applied before boding to coronal dentin

$\mathrm{NaOCl}$ applied before boding to pulp chamber dentin

$\mathrm{NaOCl}$ applied before boding to radicular dentin (simulated root canals)

$\mathrm{NaOCl}$ applied before boding to root canal dentin bonded to filling materials

$\mathrm{NaOCl}$ applied before boding to root canal dentin bonded to posts

$\mathrm{NaOCl}$ applied after etching to root canal dentin bonded to posts

$\mathrm{NaOCl}$ applied before and after etching to root canal dentin bonded to posts 


\subsection{Bonding to Coronal Dentin}

Looking at coronal dentin in particular, sodium hypochlorite has been used to pre-treat the coronal dentin surface upon which the adhesive is applied [Fig. 5 (a)] or after the application of acid etching, the first step in dentin bonding - [Fig. 5 (b)]. As observed in Fig. 5 (a), when applied before bonding to dentin, $\mathrm{NaOCl}$ was used as a solution at $0.5-6 \%$ concentration for $0.08-60 \mathrm{~min}$. The time of $\mathrm{NaOCl}$ applications follows this order: $0.25 \min >0.5 \min =10 \mathrm{~min}>1 \mathrm{~min}=60 \mathrm{~min}=0.08 \mathrm{~min}>0.3 \min =20 \min =40$ $\min =$ unknown. Human teeth $(94 \%)$ represented the most common source of coronal dentin in these studies and microtensile or shear tests (44\%) were also commonly employed to measure the bond strength to $\mathrm{NaOCl}$-treated dentin. $50 \%$ of cases reported a reduction in bond strength; $31 \%$ reported no change but only $19 \%$ reported an increase in bond strength after application of $\mathrm{NaOCl}$.

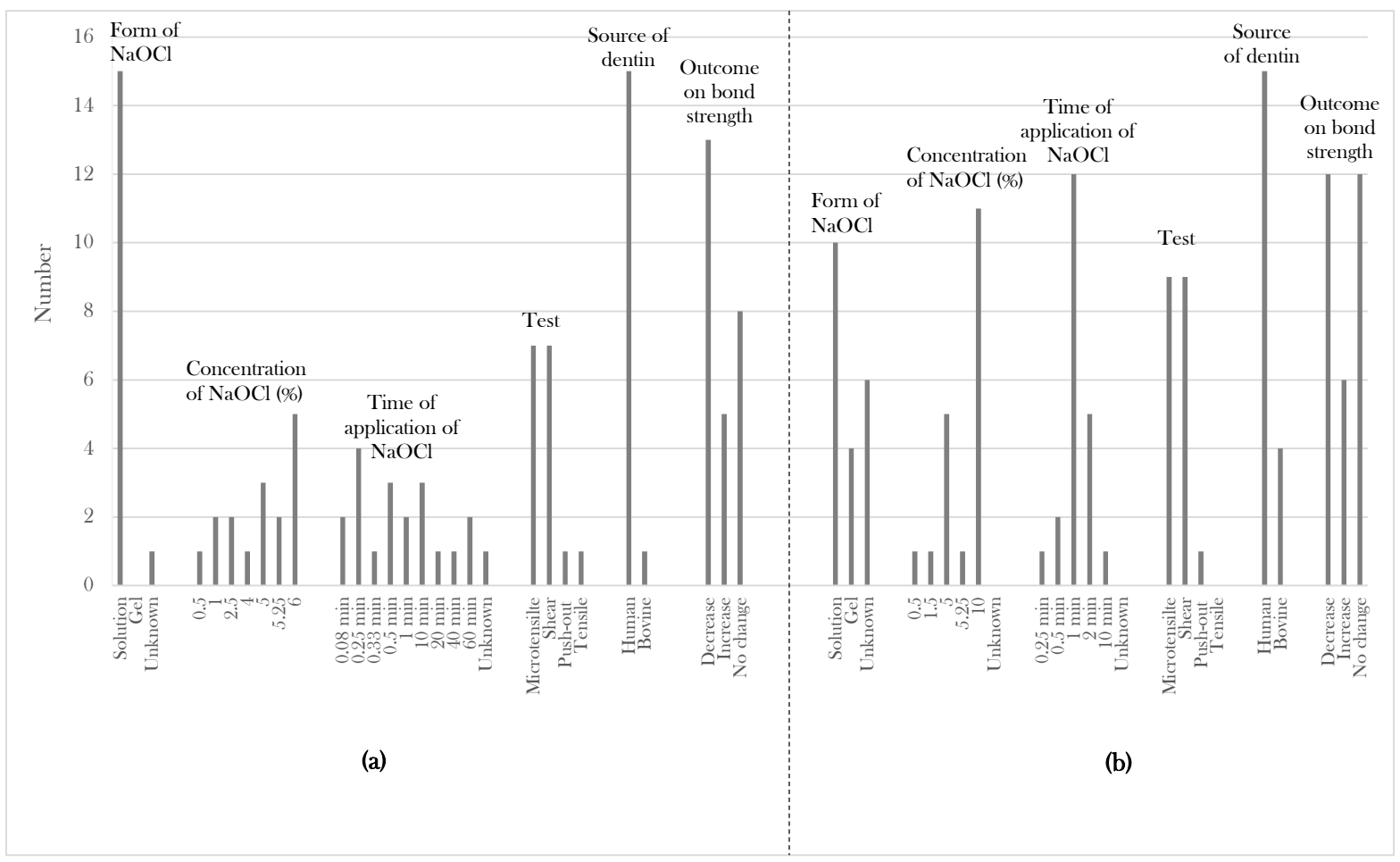




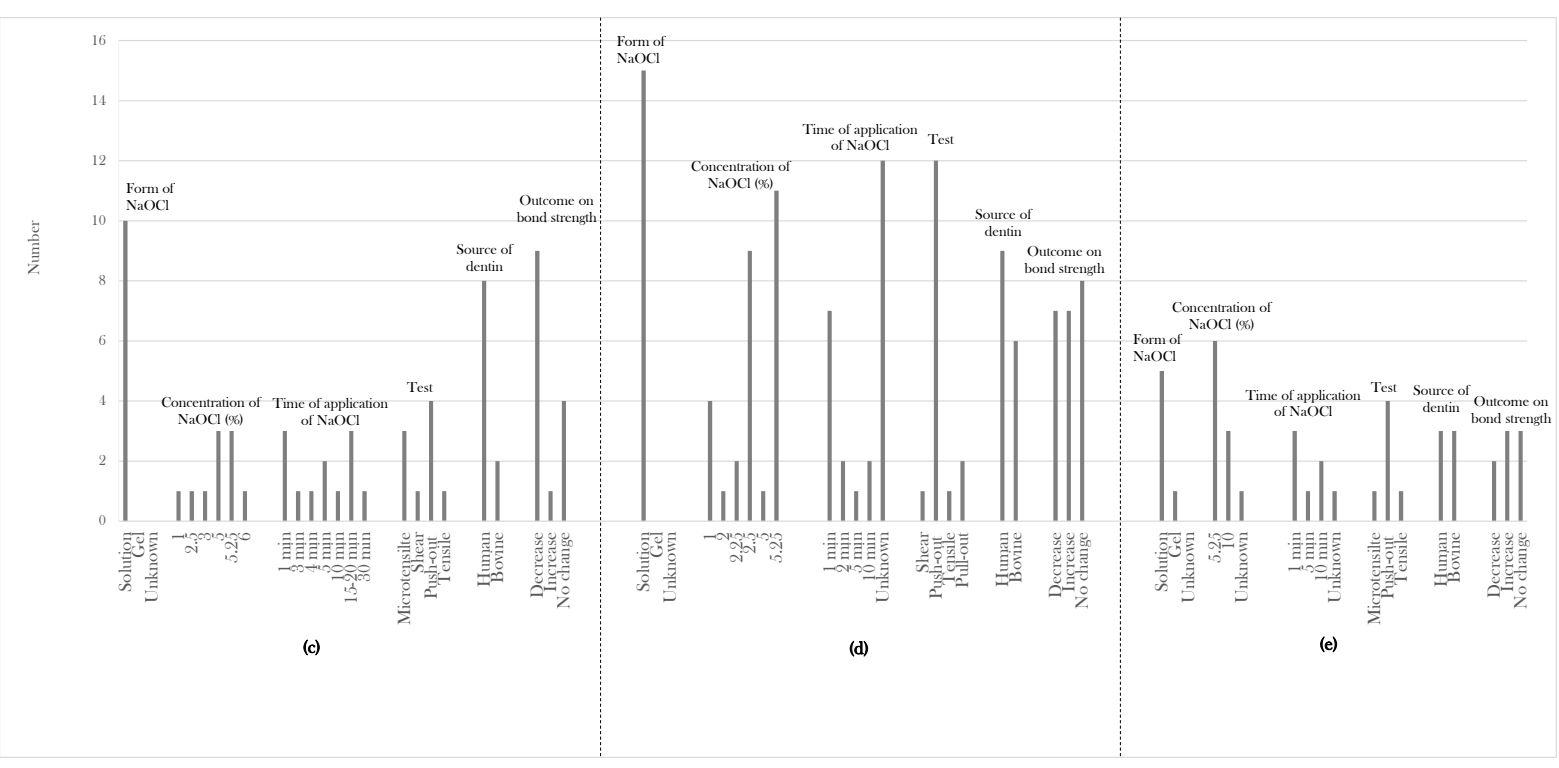

Fig. 5: Summary of studies dealt with the application of $\mathrm{NaOCl}$ before bonding (a) or after acid etching (b) of coronal dentin. Summary of studies dealt with the application of $\mathrm{NaOCl}$ before bonding to root canal dentin bonded to filling materials (c) or posts (d). Summary of studies dealt with the application of $\mathrm{NaOCl}$ after acid etching of root canal dentin bonded to posts (e).

When applied to etched dentin, $\mathrm{NaOCl}$ as a solution was used in $50 \%$ of cases at a concentration ranging from $0.5-10 \%$. for $0.25-10$ min ( 1 min was commonly used in $57 \%$ of cases). Still the microtensile or shear bond strength ( $47 \%)$ represents the most commonly used test. Human $(79 \%)$ is also the common source of dentin for these studies. $40 \%$ of cases reported a reduction in bond strength; $40 \%$ reported no change but only $20 \%$ reported an increase in bond strength after $\mathrm{NaOCl}$ application.

Looking at the outcome of studies reported in Fig. 5 (a) and (b), the increase in bond strength after application of $\mathrm{NaOCl}$ to coronal dentin was only $20 \%$ in both cases (ie before bonding or after etching). The obvious outcome in both cases is the reduction in bond strength after application of $\mathrm{NaOCl}$. 


\subsection{Bonding to Pulp Chamber Dentin}

When sodium hypochlorite was applied before bonding to pulp chamber's dentin, only four studies were conducted using $\mathrm{NaOCl}$ solutions with concentration varies from 3$5.25 \%$. for $1-30 \mathrm{~min}$. Microtensile test was used in three studies, while the tensile was used in one study. A decrease in bond strength was reported in all studies (79-82).

\subsection{Bonding to Radicular Dentin}

When sodium hypochlorite was applied before bonding to radicular dentin (ie, when simulated root canals were used for testing), only one study has been carried out (83). In this study, $\mathrm{NaOCl}$ solution (1.3\%) was used for $1 \mathrm{~min}$. Micropush-out test was used to test the bond strength of human dentin to RealSeal SE. There was an increase in bond strength.

\subsection{Bonding to Root Canal Dentin}

Generally, when $\mathrm{NaOCl}$ was used for root canal irrigation, it was always used as a solution except in just one case where gel was used (103). In most cases, it was used before the application of bonding agents; the treated root canal dentin was filled with filling materials [Fig. 5 (c)] or posts [Fig. 5 (d)]. In some cases, where posts were used, $\mathrm{NaOCl}$ application was also carried out after acid etching of dentin [Fig. 5 (e)]. Human dentin was used in $65 \%$ of cases; the rest used bovine dentin. Push-out was the most common test used for measuring the bond strength of treated dentin.

When dentin bonded to filling materials, the concentration of $\mathrm{NaOCl}$ varied from 1-6\% and the time of application ranged from 1-30 min. The outcome of $\mathrm{NaOCl}$ application 
was a reduction in bond strength in $64 \%$ of cases, no change in $29 \%$ and an increase in only $7 \%$.

When dentin bonded to posts and $\mathrm{NaOCl}$ applied before bonding, the concentration of $\mathrm{NaOCl}$ varied from $1-5.25 \%$ and the time of application ranged from 1-10 min. The outcome of $\mathrm{NaOCl}$ application was no change in $36 \%$ of cases, a reduction in bond strength in $32 \%$ of cases and an increase in only $32 \%$.

When dentin bonded to posts and $\mathrm{NaOCl}$ applied after etching, the concentration of $\mathrm{NaOCl}$ was mostly $5.25 \%$ and $10 \%$ and the time of application ranged from $1-10 \mathrm{~min}$. The outcome of $\mathrm{NaOCl}$ application was no change in $37.5 \%$ of cases, an increase in $37.5 \%$ of cases while a redcution in $25 \%$ of cases.

\subsection{Risk of Bias Assessment}

The results of risk of bias assesement is give in Table 3. Only 11 articles showed high risk of bias (ie 15.9\%); 47 articles have medium risk of bias (68.1\%). The remaining 11 articles have low risk of bias (15.9\%); most of studies were carried out on root canal dentin irrigated with sodium hypochlorite before bonding to posts. As a standardization of technique, one operator performed the procedures in only $8 / 69$ studies (11.6\%). Only $23 / 69$ studies (33.3\%) carried the randomization of samples. No blinding was performed in the data analysis; only one study out of 69 (1.4\%) performed blinding. 14 studies out of $69(20.3 \%)$ did not follow the manufacturer instructions during preparation of materials used.

Summary of outcome of all included articles has been presented in Table 4 (a). Considering the outcome of articles with high risk of bias (low methodological quality), there is a strong evidence to support that $2.5-10 \%$ sodium hypochlorite has no effect 
on bond strength of coronal or root canal dentin with various materials. Similar outcome was obtained with articles having low risk of bias (high methodological quality). On the other hand, considering the outcome of articles with medium risk of bias (low methodological quality), there is a strong evidence to support that $2.5-10 \%$ sodium hypochlorite reduces the bond strength of coronal or root canal dentin with various materials - Table 4 (b \& c). 
Table 3: Risk of bias assessment for studies included in this review.

\begin{tabular}{|c|c|c|c|c|c|c|c|c|}
\hline No. & Author & $\begin{array}{l}\text { Presence of } \\
\text { control }\end{array}$ & $\begin{array}{l}\text { Description } \\
\text { of sample } \\
\text { size }\end{array}$ & $\begin{array}{l}\text { Randomization } \\
\text { of samples }\end{array}$ & $\begin{array}{c}\text { Procedures } \\
\text { carried by } \\
\text { one } \\
\text { operator }\end{array}$ & $\begin{array}{l}\text { Blinding of } \\
\text { operator }\end{array}$ & $\begin{array}{l}\text { Materials used } \\
\text { according to } \\
\text { manufacturers' } \\
\text { instruction }\end{array}$ & Risk of bias \\
\hline 1. & Francescantonio et al., (45) & $\mathrm{Y}$ & $\mathrm{Y}$ & $\mathrm{N}$ & $\mathrm{N}$ & $\mathrm{N}$ & $\mathrm{Y}$ & Medium \\
\hline 2. & Prati et al., (30) & $\mathrm{Y}$ & $\mathrm{N}$ & $\mathrm{N}$ & $\mathrm{N}$ & $\mathrm{N}$ & $\mathrm{Y}$ & High \\
\hline 3. & Uceda-Gomez et al., (46) & $\mathrm{Y}$ & $\mathrm{Y}$ & $\mathrm{N}$ & $\mathrm{N}$ & $\mathrm{N}$ & $\mathrm{Y}$ & Medium \\
\hline 4. & Osorio et al., (47) & $\mathrm{Y}$ & $\mathrm{Y}$ & $\mathrm{Y}$ & $\mathrm{N}$ & $\mathrm{N}$ & $\mathrm{Y}$ & Medium \\
\hline 5. & Yiu et al.,(48) & $\mathrm{Y}$ & $\mathrm{Y}$ & $\mathrm{N}$ & $\mathrm{N}$ & $\mathrm{N}$ & $\mathrm{Y}$ & Medium \\
\hline 6. & Saboia et al., (49) & $\mathrm{Y}$ & $\mathrm{Y}$ & $\mathrm{Y}$ & $\mathrm{N}$ & $\mathrm{N}$ & $\mathrm{Y}$ & Medium \\
\hline 7. & Baseggio et al., (50) & $\mathrm{Y}$ & $\mathrm{Y}$ & $\mathrm{Y}$ & $\mathrm{N}$ & $\mathrm{N}$ & $\mathrm{N}$ & Medium \\
\hline 8. & dos Santos et al., (51) & $\mathrm{Y}$ & $\mathrm{Y}$ & $\mathrm{Y}$ & $\mathrm{N}$ & $\mathrm{N}$ & $\mathrm{N}$ & Medium \\
\hline 9. & Perdigão et al., (52) & $\mathrm{Y}$ & $\mathrm{Y}$ & $\mathrm{Y}$ & $\mathrm{N}$ & $\mathrm{N}$ & $\mathrm{Y}$ & Medium \\
\hline 10. & Uceda-Gomez et al., (53) & $\mathrm{Y}$ & $\mathrm{Y}$ & $\mathrm{Y}$ & $\mathrm{Y}$ & $\mathrm{N}$ & $\mathrm{Y}$ & Low \\
\hline 11. & Manjunath \& Vinutha (54) & $\mathrm{Y}$ & $\mathrm{Y}$ & $\mathrm{Y}$ & $\mathrm{N}$ & $\mathrm{N}$ & $\mathrm{N}$ & Medium \\
\hline 12. & Correr et al., (55) & $\mathrm{Y}$ & $\mathrm{Y}$ & $\mathrm{Y}$ & $\mathrm{N}$ & $\mathrm{N}$ & $\mathrm{Y}$ & Medium \\
\hline 13. & Montagner et al., (56) & $\mathrm{Y}$ & $\mathrm{Y}$ & $\mathrm{Y}$ & $\mathrm{Y}$ & $\mathrm{N}$ & $\mathrm{Y}$ & Low \\
\hline 14. & Lisboa et al., (57) & $\mathrm{Y}$ & $\mathrm{Y}$ & $\mathrm{N}$ & $\mathrm{N}$ & $\mathrm{N}$ & $\mathrm{N}$ & High \\
\hline 15. & Aguilera et al., (58) & $\mathrm{Y}$ & $\mathrm{Y}$ & $\mathrm{Y}$ & $\mathrm{N}$ & $\mathrm{N}$ & $\mathrm{Y}$ & Medium \\
\hline 16. & de-Souza et al., (59) & $\mathrm{Y}$ & $\mathrm{Y}$ & $\mathrm{Y}$ & $\mathrm{N}$ & $\mathrm{N}$ & $\mathrm{Y}$ & Medium \\
\hline 17. & Sauro et al., (60) & $\mathrm{Y}$ & $\mathrm{Y}$ & $\mathrm{N}$ & $\mathrm{N}$ & $\mathrm{N}$ & $\mathrm{N}$ & High \\
\hline 18. & Goncalves et al., (61) & $\mathrm{Y}$ & $\mathrm{Y}$ & $\mathrm{Y}$ & $\mathrm{N}$ & $\mathrm{N}$ & $\mathrm{Y}$ & Medium \\
\hline 19. & Arias et al., (62) & $\mathrm{Y}$ & $\mathrm{Y}$ & $\mathrm{Y}$ & $\mathrm{N}$ & $\mathrm{N}$ & $\mathrm{N}$ & Medium \\
\hline 20. & Taniguchi et al., (63) & $\mathrm{Y}$ & $\mathrm{Y}$ & $\mathrm{N}$ & $\mathrm{N}$ & $\mathrm{N}$ & $\mathrm{Y}$ & Medium \\
\hline 21. & Stevens et al., (64) & $\mathrm{Y}$ & $\mathrm{Y}$ & $\mathrm{N}$ & $\mathrm{N}$ & $\mathrm{N}$ & $\mathrm{Y}$ & High \\
\hline 22. & Cecchin et al., (65) & $\mathrm{Y}$ & $\mathrm{Y}$ & $\mathrm{Y}$ & $\mathrm{N}$ & $\mathrm{N}$ & $\mathrm{Y}$ & Medium \\
\hline 23. & Hassan et al., (66) & $\mathrm{Y}$ & $\mathrm{Y}$ & $\mathrm{N}$ & $\mathrm{N}$ & $\mathrm{N}$ & $\mathrm{N}$ & High \\
\hline 24. & Ebrahimi-Chaharom et al., (67) & $\mathrm{Y}$ & $\mathrm{Y}$ & $\mathrm{Y}$ & $\mathrm{N}$ & $\mathrm{N}$ & $\mathrm{Y}$ & Medium \\
\hline 25. & Gönülol et al., (68) & $\mathrm{Y}$ & $\mathrm{Y}$ & $\mathrm{Y}$ & $\mathrm{N}$ & $\mathrm{N}$ & $\mathrm{Y}$ & Medium \\
\hline 26. & Farina et al., (69) & $\mathrm{Y}$ & $\mathrm{Y}$ & $\mathrm{Y}$ & $\mathrm{N}$ & $\mathrm{N}$ & $\mathrm{Y}$ & Medium \\
\hline 27. & Nassar et al., (70) & $\mathrm{Y}$ & $\mathrm{Y}$ & $\mathrm{Y}$ & $\mathrm{N}$ & $\mathrm{N}$ & $\mathrm{N}$ & Medium \\
\hline 28. & Abo et al., (71) & $\mathrm{Y}$ & $\mathrm{Y}$ & $\mathrm{Y}$ & $\mathrm{N}$ & $\mathrm{N}$ & $\mathrm{Y}$ & Medium \\
\hline 29. & Saber \& El-Askary (72) & $\mathrm{Y}$ & $\mathrm{Y}$ & $\mathrm{N}$ & $\mathrm{N}$ & $\mathrm{N}$ & $\mathrm{Y}$ & Medium \\
\hline 30. & Kunawarote et al., (73) & $\mathrm{Y}$ & $\mathrm{Y}$ & $\mathrm{Y}$ & $\mathrm{N}$ & $\mathrm{N}$ & $\mathrm{Y}$ & Medium \\
\hline 31. & Kambara et al., (74) & $\mathrm{Y}$ & $\mathrm{Y}$ & $\mathrm{Y}$ & $\mathrm{N}$ & $\mathrm{N}$ & $\mathrm{N}$ & Medium \\
\hline 32. & Ayad \& Garcia-Godoy (75) & $\mathrm{Y}$ & $\mathrm{Y}$ & $\mathrm{Y}$ & $\mathrm{Y}$ & $\mathrm{N}$ & $\mathrm{N}$ & Medium \\
\hline 33. & Kasraei et al., (76) & $\mathrm{Y}$ & $\mathrm{Y}$ & $\mathrm{Y}$ & $\mathrm{Y}$ & $\mathrm{N}$ & $\mathrm{Y}$ & Low \\
\hline 34. & Sasafuchi et al.., (77) & $\mathrm{Y}$ & $\mathrm{Y}$ & $\mathrm{N}$ & $\mathrm{N}$ & $\mathrm{N}$ & $\mathrm{Y}$ & Medium \\
\hline 35. & Prasansuttiporn et al., (78) & $\mathrm{Y}$ & $\mathrm{Y}$ & $\mathrm{N}$ & $\mathrm{N}$ & $\mathrm{N}$ & $\mathrm{Y}$ & Medium \\
\hline 36. & Vongphan et al., (79) & $\mathrm{Y}$ & $\mathrm{Y}$ & $\mathrm{N}$ & $\mathrm{N}$ & $\mathrm{N}$ & $\mathrm{Y}$ & Medium \\
\hline 37. & Bhat Gorwish et al., (80) & $\mathrm{Y}$ & $\mathrm{Y}$ & $\mathrm{Y}$ & $\mathrm{N}$ & $\mathrm{N}$ & $\mathrm{Y}$ & Medium \\
\hline 38. & Ozturk \& Ozer (81) & $\mathrm{Y}$ & $\mathrm{Y}$ & $\mathrm{N}$ & $\mathrm{N}$ & $\mathrm{N}$ & $\mathrm{Y}$ & Medium \\
\hline 39. & Santos et al., (82) & $\mathrm{Y}$ & $\mathrm{Y}$ & $\mathrm{N}$ & $\mathrm{N}$ & $\mathrm{N}$ & $\mathrm{Y}$ & Medium \\
\hline 40. & Shretha et al., (83) & $\mathrm{Y}$ & $\mathrm{Y}$ & $\mathrm{Y}$ & $\mathrm{N}$ & $\mathrm{N}$ & $\mathrm{Y}$ & Medium \\
\hline 41. & Morris et al., (84) & $\mathrm{Y}$ & $\bar{Y}$ & $\mathrm{Y}$ & $\mathrm{N}$ & $\mathrm{N}$ & $\mathrm{Y}$ & Medium \\
\hline 42. & Manimaran et al., (85) & $\mathrm{Y}$ & $\mathrm{Y}$ & $\mathrm{Y}$ & $\mathrm{N}$ & $\mathrm{N}$ & $\mathrm{Y}$ & Medium \\
\hline
\end{tabular}




\begin{tabular}{|c|c|c|c|c|c|c|c|c|}
\hline 43. & Erdemire et al., (21) & $\bar{Y}$ & $\bar{Y}$ & $\bar{Y}$ & $\mathrm{~N}$ & $\mathrm{~N}$ & $\bar{Y}$ & Medium \\
\hline 44. & Gu et al., (43) & $\mathrm{Y}$ & $\mathrm{Y}$ & $\mathrm{Y}$ & $\mathrm{N}$ & $\mathrm{Y}$ & $\mathrm{Y}$ & Low \\
\hline 45. & Ari et al., (86) & $\mathrm{Y}$ & $\mathrm{Y}$ & $\mathrm{Y}$ & $\mathrm{N}$ & $\mathrm{N}$ & $\mathrm{Y}$ & Medium \\
\hline 46. & Stelzer et al., (87) & $\mathrm{Y}$ & $\mathrm{Y}$ & $\mathrm{N}$ & $\mathrm{N}$ & $\mathrm{N}$ & $\mathrm{N}$ & High \\
\hline 47. & Haragushiku et al., (88) & $\mathrm{Y}$ & $\mathrm{Y}$ & $\mathrm{Y}$ & $\mathrm{N}$ & $\mathrm{N}$ & $\mathrm{Y}$ & Medium \\
\hline 48. & Ishizuka et al., (89) & $\mathrm{N}$ & $\mathrm{Y}$ & $\mathrm{N}$ & $\mathrm{N}$ & $\mathrm{N}$ & $\mathrm{Y}$ & High \\
\hline 49. & Rocha et al., (42) & $\mathrm{Y}$ & $\mathrm{Y}$ & $\mathrm{Y}$ & $\mathrm{N}$ & $\mathrm{N}$ & $\mathrm{Y}$ & Medium \\
\hline 50. & Weston et al., (31) & $\mathrm{Y}$ & $\mathrm{Y}$ & $\bar{Y}$ & $\mathrm{~N}$ & $\mathrm{~N}$ & $\bar{Y}$ & Medium \\
\hline 51. & Bournziniat et al., (90) & $\mathrm{Y}$ & $\mathrm{Y}$ & $\mathrm{Y}$ & $\mathrm{N}$ & $\mathrm{N}$ & $\mathrm{Y}$ & Medium \\
\hline 52. & Lacerda et al., (91) & $\mathrm{Y}$ & $\mathrm{Y}$ & $\mathrm{N}$ & $\mathrm{N}$ & $\mathrm{N}$ & $\mathrm{Y}$ & Medium \\
\hline 53. & Khoroushi et al., (92) & $\mathrm{Y}$ & $\mathrm{Y}$ & $\mathrm{Y}$ & $\mathrm{N}$ & $\mathrm{N}$ & $\mathrm{Y}$ & Medium \\
\hline 54. & Arisu et al., (93) & $\mathrm{Y}$ & $\mathrm{Y}$ & $\mathrm{Y}$ & $\mathrm{N}$ & $\mathrm{N}$ & $\mathrm{Y}$ & Medium \\
\hline 55. & Alkhudhairy \& Bin-Shuwaish (94) & $\mathrm{Y}$ & $\mathrm{Y}$ & $\mathrm{Y}$ & $\mathrm{N}$ & $\mathrm{N}$ & $\mathrm{Y}$ & Medium \\
\hline 56. & Faria-e-Silva et al., (95) & $\mathrm{Y}$ & $\mathrm{Y}$ & $\mathrm{N}$ & $\mathrm{N}$ & $\mathrm{N}$ & $\mathrm{N}$ & High \\
\hline 57. & Bueno et al., (96) & $\mathrm{Y}$ & $\mathrm{Y}$ & $\mathrm{Y}$ & $\mathrm{Y}$ & $\mathrm{N}$ & $\mathrm{Y}$ & Low \\
\hline 58. & Bitter et al., (97) & $\mathrm{Y}$ & $\mathrm{Y}$ & $\mathrm{Y}$ & $\mathrm{Y}$ & $\mathrm{N}$ & $\mathrm{Y}$ & Low \\
\hline 59. & Ertas et al., (98) & $\mathrm{Y}$ & $\mathrm{Y}$ & $\mathrm{N}$ & $\mathrm{N}$ & $\mathrm{N}$ & $\mathrm{Y}$ & Medium \\
\hline 60. & Pelegrine et al., (99) & $\mathrm{Y}$ & $\mathrm{Y}$ & $\mathrm{Y}$ & $\mathrm{Y}$ & $\mathrm{N}$ & $\mathrm{Y}$ & Low \\
\hline 61. & Haragushiku et al., (100) & $\mathrm{Y}$ & $\mathrm{Y}$ & $\mathrm{N}$ & $\mathrm{N}$ & $\mathrm{N}$ & $\mathrm{Y}$ & Medium \\
\hline 62. & Kaif and Raj (101) & $\mathrm{Y}$ & $\mathrm{Y}$ & $\mathrm{N}$ & $\mathrm{N}$ & $\mathrm{N}$ & $\mathrm{N}$ & High \\
\hline 63. & Saraiva et al., (44) & $\mathrm{Y}$ & $\mathrm{Y}$ & $\mathrm{Y}$ & $\mathrm{Y}$ & $\mathrm{N}$ & $\mathrm{Y}$ & Low \\
\hline 64. & Cecchin et al., (102) & $\mathrm{Y}$ & $\mathrm{Y}$ & $\mathrm{Y}$ & $\mathrm{Y}$ & $\mathrm{N}$ & $\mathrm{Y}$ & Low \\
\hline 65. & Inoue et al., (103) & $\bar{Y}$ & $\mathrm{~N}$ & $\mathrm{~N}$ & $\mathrm{~N}$ & $\mathrm{~N}$ & $\mathrm{~N}$ & High \\
\hline 66. & Mao et al., (104) & $\mathrm{Y}$ & $\mathrm{Y}$ & $\mathrm{Y}$ & $\mathrm{N}$ & $\mathrm{N}$ & $\mathrm{Y}$ & Medium \\
\hline 67. & Varela et al., (105) & $\bar{Y}$ & $\mathrm{Y}$ & $\mathrm{Y}$ & $\mathrm{Y}$ & $\mathrm{N}$ & $\mathrm{Y}$ & Low \\
\hline 68. & Furuse et al., (106) & $\mathrm{Y}$ & $\mathrm{Y}$ & $\mathrm{N}$ & $\mathrm{N}$ & $\mathrm{N}$ & $\mathrm{Y}$ & High \\
\hline 69. & da Cunba et al., (107) & $\mathrm{Y}$ & $\mathrm{Y}$ & $\mathrm{Y}$ & $\mathrm{Y}$ & $\mathrm{N}$ & $\mathrm{Y}$ & Low \\
\hline
\end{tabular}

$\mathrm{NaOCl}$ applied after etching ( $1^{\text {st }}$ step of bonding) to coronal dentin

$\mathrm{NaOCl}$ applied before boding to coronal dentin

$\mathrm{NaOCl}$ applied before boding to pulp chamber dentin

$\mathrm{NaOCl}$ applied before boding to radicular dentin (simulated root canals)

$\mathrm{NaOCl}$ applied before boding to root canal dentin bonded to filling materials

$\mathrm{NaOCl}$ applied before boding to root canal dentin bonded to posts

$\mathrm{NaOCl}$ applied after etching to root canal dentin bonded to posts

$\mathrm{NaOCl}$ applied before and after etching to root canal dentin bonded to posts

Additional article for antioxidants to reverse the action of $\mathrm{NaOCl}$ 
Table 4: (a) Detailed summary of outocme from all included (whether low, medium or high risk of bias) studies to $\mathrm{NaOCl}$ application on dentin bond strength. CD: coronal dentin. RCD: root canal dentin. F: filling materials. P: posts.

\begin{tabular}{l|c|c|c}
\hline \multirow{2}{*}{ Step of NaOCI Application } & \multicolumn{3}{|c}{ Outcome to NaOCI Application } \\
\cline { 2 - 4 } & $\begin{array}{c}\text { Decrease } \\
\text { (\%) }\end{array}$ & $\begin{array}{c}\text { Increase } \\
\text { (\%) }\end{array}$ & $\begin{array}{c}\text { No Change } \\
\text { (\%) }\end{array}$ \\
\hline Before bonding to CD & 50 & 19 & 31 \\
\hline After etching to CD & 40 & 20 & 40 \\
\hline Before bonding to RCD bonded to F & 64 & 7 & 29 \\
\hline Before bonding to RCD bonded to P & 32 & 32 & 36 \\
\hline After bonding to RCD bonded to P & 25 & 37.5 & 37.5 \\
\hline
\end{tabular}

(b) Summary of outcome to $\mathrm{NaOCl}$ application on coronal dentin bond strength.

\begin{tabular}{l|c|c|c}
\hline \multirow{2}{*}{ Type of articles (No.) } & \multicolumn{3}{|c}{ Outcome to NaOCI Application } \\
\cline { 2 - 4 } & $\begin{array}{c}\text { Decrease } \\
(\%)\end{array}$ & $\begin{array}{c}\text { Increase } \\
(\%)\end{array}$ & $\begin{array}{c}\text { No Change } \\
\text { (\%) }\end{array}$ \\
\hline Low risk of bias articles (3) & - & - & 100 \\
\hline Medium risk of bias articles (27) & 54.5 & 18.2 & 27.3 \\
\hline High risk of bias articles (5) & 27.3 & 27.3 & 45.5 \\
\hline
\end{tabular}

(c) Summary of outcome to $\mathrm{NaOCl}$ application on root canal dentin bond strength.

\begin{tabular}{l|c|c|c}
\hline \multirow{2}{*}{ Type of articles (No.) } & \multicolumn{3}{|c}{ Outcome to NaOCI Application } \\
\cline { 2 - 4 } & $\begin{array}{c}\text { Decrease } \\
\text { (\%) }\end{array}$ & $\begin{array}{c}\text { Increase } \\
\text { (\%) }\end{array}$ & $\begin{array}{c}\text { No Change } \\
\text { (\%) }\end{array}$ \\
\hline Low risk of bias articles (8) & 27.3 & 18.2 & 54.5 \\
\hline Medium risk or bias articles (20) & 63.6 & 22.7 & 13.6 \\
\hline High risk of bias articles (6) & 33.3 & 22.2 & 44.4 \\
\hline
\end{tabular}

\section{Discussion}

Main Findings: Within the limitation of this review, the evidence from articles with high (low quality) or low risk of bias (high quality) indicates that $2.5-10 \%$ sodium hypochlorite has no effect on bond strength of dentin (coronal or root canal) with various materials. The evidence from articles with medium risk of bias (low quality) 
indicates that $2.5-10 \%$ sodium hypochlorite reduced the bond strength of dentin (coronal or root canal) with various materials.

Strength and Limitations: To the best of authors knowledge, this is the first study to systematically review and assess a wide range of experimental-based articles considering the effect of sodium hypochlorite on bond strength of dentin to various restorative materials. This review was based on comprehesive search strategies using PubMed, Google Scholar, Cochrane Library and OpenThesis database. A manual search was also conducted for references of identified articles. Risk of bias assessment showed that 11 articles out of 69 have low risk of bias (15.9\% ); 8 articles used root canal dentin to study the effect of sodium hypochlorite (ie more relevant to endodontic use).

The limitations with review however include: (1) there was a significant heterogeneity in testing methodologies used to study the effect of sodium hypochlorite on bond strength to dentin. Regardless of heterogeneity in methodology, the outocme obtained from articles with low risk of bias are highly correlated for both coronal and root canal dentin. The same was also observed with the outcome obtained from articles with medium risk of bias. (2) Although in vitro studies attempt to simulate the clinical situations, the clinical trials are the best way to provide a relevant evidence on the effectiveness of any material. However, there is no clinical trials have been conducted on sodium hypochlorite and its effect on dentin bonding to various materials. Therefore, correlating the clinical data with in vitro studies was not feasible. (3) Because of heterogeneity of the studies, it was not feasible to conduct a metaanalysis. 
Clinical Significance: This review suggest the need for the development of a standaridized method to get relevant data from the patients receiving sodium hypochlorite as an irrigant during endodontic treatment to reflect its action on adhesion of dentin to various materials.

\section{Conflict of Interest}

"The author(s) report no conflict of interest for this study."

\section{References}

1. Modh H, Sequeira V, Belur A, Neemaarun, Dhas S, Fernandes G. Newer Trends in Endodontic Treatment: A Review. 2018.

2. Peters OA, Schönenberger K, Laib A. Effects of four Ni-Ti preparation techniques on root canal geometry assessed by micro computed tomography. Int Endod J 2001;34(3):221-230.

3. Mohammadi Z. Sodium hypochlorite in endodontics: an update review. Int Dent J. 2008; 58(6):329-341.

4. Haapasalo M, Endal U, Zandi H, Coil JM. Eradication of endodontic infection by instrumentation and irrigation solutions. Endodontic Topics 2005;10(1):77-102.

5. Haapasalo M, Shen Y, Qian W, Gao Y. Irrigation in endodontics. Dent Clin N Am 2010;54:291312.

6. Spencer HR, Ike V, Brennan PA. Review: the use of sodium hypochlorite in endodontics potential complications and their management. Bdj 2007;202:555.

7. Siqueira JF, Machado AG, Silveira RM, Lopes H, de Uzeda M. Evaluation of the effectiveness of sodium hypochlorite used with three irrigation methods in the elimination of Enterococcus faecalis from the root canal, in vitro. Int Endod J. 1997;30(4):279-282.

8. Retamozo B, Shabahang S, Johnson N, Aprecio RM, Torabinejad M. Minimum contact time and concentration of sodium hypochlorite required to eliminate Enterococcus faecalis. J Endod 2010;36(3):520-523.

9. del Carpio-Perochena A, Bramante CM, Duarte MH, Bombarda de Andrade F, Graeff MZ, Marciano da Silva $\mathrm{M}$, et al. Effect of temperature, concentration and contact time of sodium hypochlorite on the treatment and revitalization of oral biofilms. J Dent Res Dent Clin Dent Prospects 2015;9(4):209-215.

10. Radcliffe CE, Potouridou L, Qureshi R, Habahbeh N, Qualtrough A, Worthington $H$, et al. Antimicrobial activity of varying concentrations of sodium hypochlorite on the endodontic microorganisms Actinomyces israelii, A. naeslundii, Candida albicans and Enterococcus faecalis. International Endodontic Journal 2004;37:438-446.

11. Reis Só MV, Vier-Pelisser FV, Darcie MS, Smaniotto DGR, Montagner F, Kuga MC. Pulp tissue dissolution when the use of sodium hypochlorite and EDTA alone or associated Rev Odonto Cienc 2011;26(2):156-160.

12. Taneja S, Mishra N, Malik S. Comparative evaluation of human pulp tissue dissolution by different concentrations of chlorine dioxide, calcium hypochlorite and sodium hypochlorite: An in vitro study. 2014 17(6):541-545.

13. Abou-Rass M, Oglesby SW. The effects of temperature, concentration and tissue type on the solvent ability of sodium hypochlorite. J Endod. 1981;7:376-377. 
14. Cunningham WT, Balekjian AY. Effect of temperature on collagen-dissolving ability of sodium hypochlorite endodontic irrigant. Oral Surg Oral Med Oral Pathol. 1980;49:175-177.

15. Palazzi F, Morra M, Mohammadi Z, Grandini S, Giardino L. Comparison of the surface tension of $5.25 \%$ sodium hypochlorite solution with three new sodium hypochlorite-based endodontic irrigants. International Endodontic Journal 2012;45:129-135.

16. Mirseifinejad R, Tabrizizade M, Davari A, Mehravar F. Efficacy of Different Root Canal Irrigants on Smear Layer Removal after Post Space Preparation: A Scanning Electron Microscopy Evaluation. Iranian endodontic journal 2017;12(2):185-190.

17. Machado R, Comparin D, Engelke Back EDE, Roberti Garcia LdF, Alberton LR. Residual smear layer after root canal instrumentation by using Niti, M-Wire and CM-Wire instruments: A scanning electron microscopy analysis. European journal of dentistry 2018;12(3):403-409.

18. Kokkas AB, Boutsioukis A, Vassiliadis LP, Stavrianos CK. The influence of the smear layer on dentinal tubule penetration depth by three different root canal sealers: an in vitro study. J Endod 2004;30(2):100-102.

19. Shokouhinejad N, Sabeti M, Gorjestani H, Saghiri MA, Lotfi M, Hoseini A. Penetration of Epiphany, Epiphany Self-Etch, and AH Plus into Dentinal Tubules: A Scanning Electron Microscopy Study. Journal of Endodontics 2011;37(9):1316-1319.

20. Niu W, Yoshioka T, Kobayashi C, Suda H. A scanning electron microscopic study of dentinal erosion by final irrigation with EDTA and $\mathrm{NaOCl}$ solutions. Int Endod J 2002;35(11):934-939.

21. Erdemir A, Ari H, Güngüneş $H$, Belli $S$. Effect of medications for root canal treatment on bonding to root canal dentin. J Endod. 2004;30(2):113-116.

22. Erdemir A, Eldeniz A, Belli S, H Pashley D. Effect of Solvents on Bonding to Root Canal Dentin. 2004.

23. Erdemir A, Eldeniz AU, Belli S, Pashley DP. Effect of solvents on bonding to root canal dentin. Journal of Endodontics 2004;30(8):589-591.

24. Sabir Muliyar KAS, Rekha P Thankachan, P G Francis, C S Jayapalan, and K A Abdul Hafiz. Microleakage in Endodontics. J Int Oral Health 2014;6(6):99-104.

25. Kantheti Sirisha TR, Yalavarthi Ravi Shankar, and Pabbati Ravikumar. Validity of bond strength tests: A critical review: Part I. J Conserv Dent. 2014;17(4):305-311.

26. Heintze SD. Systematic reviews: I. The correlation between laboratory tests on marginal quality and bond strength. II. The correlation between marginal quality and clinical outcome. The journal of adhesive dentistry 2007;9 Suppl 1:77-106.

27. Heintze SD. Clinical relevance of tests on bond strength, microleakage and marginal adaptation. Dental Materials 2013;29(1):59-84.

28. Elkhatib H, Nakajima M, Hiraishi N, Kitasako Y, Tagami J, Nomura S. Surface PH and bond strength of a self-etching primer/adhesive system to intracoronal dentin after application of hydrogen peroxide bleach with sodium perborate. 2002.

29. Wakabayashi Y, Kondou Y, Suzuki K, Yatani H, Yamashita A. Effect of dissolution of collagen on adhesion to dentin. Int J Prosthodont. 1994;7(4):302-306.

30. Prati C, Chersoni S, Pashley DH. Effect of removal of surface collagen fibrils on resin-dentin bonding. Dent Mater. 1999;15(5):323-331.

31. Weston $\mathrm{CH}$, Ito S, Wadgaonkar B, Pashley DH. Effects of time and concentration of sodium ascorbate on reversal of $\mathrm{NaOCl}$-induced reduction in bond strengths. J Endod. 2007;33(7):879-881.

32. Nikaido T, Takano Y, Sasafuchi Y, Burrow MF, Tagami J. Bond strengths to endodonticallytreated teeth. Am J Dent. 1999;12(4):177-180.

33. Hawkins CL, M.J. D. Hypochlorite-induced oxidation of proteins in plasma: formation of chloramines and nitrogen-centred radicals and their role in protein fragmentation. Biochem. J. 1999;340:539-548

34. F. Salama HB, F. Al-Yahya,, Al-Mofareh S. The effect of cavity disinfectants on microleakage of composite restorations in primary teeth. European Journal of Paediatric Dentistry 2015;16(4):295300. 
35. Dikmen B, Tarim B. The effect of endodontic irrigants on the microtensile bond strength of different dentin adhesives. Nigerian journal of clinical practice 2018;21(3):280-286.

36. Mandke L. Importance of coronal seal: Preventing coronal leakage in endodontics. Journal of Restorative Dentistry 2016;4(3):71-75.

37. Nakabayashi N, Nakamura M, Yasuda N. Hybrid layer as a dentin-bonding mechanism. Journal of esthetic dentistry 1991;3(4):133-138.

38. Salvio LA, Hipólito VD, Martins AL, de Goes MF. Hybridization quality and bond strength of adhesive systems according to interaction with dentin. European journal of dentistry 2013;7(3):315326.

39. Mountouris G, Silikas N, Eliades G. Effect of sodium hypochlorite treatment on the molecular composition and morphology of human coronal dentin. The journal of adhesive dentistry 2004;6(3):175-182.

40. Dayem R, Tameesh M. A new concept in hybridization: Bromelain enzyme for deproteinizing dentin before application of adhesive system. Contemporary Clinical Dentistry 2013;4(4):421-426.

41. Emad AIShwaimi DB, Reem Ajaj, Saad Al-Shahrani, Khalid Almas, Abdul Majeed. In Vitro Antimicrobial Effectiveness of Root Canal Sealers against Enterococcus faecalis: A Systematic Review. J Endod. 2016;42(11):1588-1597.

42. Rocha AW, de Andrade CD, Leitune VCB, Collares FM, Samuel SMW, Greeca FS, et al. Influence of endodontic irrigants on resin sealer bond strength to radicular dentin. Bull Tokyo Dent Coll 2012;53(1):1-7.

43. Gu X-H, Mao C-Y, Liang C, Wang H-M, Kern M. Does endodontic post spaceirrigation affect smear layer removal and bonding effectiveness? . Eur J Oral Sci 2009;117:597-603.

44. Saraiva LO, Aguiar TR, Costa L, Correr-Sobrinho L, Muniz L, Mathias P. Effect of different adhesion strategies on fiber post cementation: Push-out test and scanning electron microscopy analysis. Contemp Clin Dent. 2013;4(4):443-447.

45. Francescantonio MD, Nurrohman H, Takagaki T, Nikaido T, Tagami J, Giannini M. Sodium hypochlorite effects on dentin bond strength and acid-base resistant zone formation by adhesive systems. Braz J Oral Sci 2015;14(4):334-340.

46. Uceda-Gomez N, Reis A, Carrilho MRd-O, Loguercio AD, Filho LER. Effect of sodim hypochlorite on the bond strength of an adhesive system to superficial and deep dentin. J Appl Oral Sci 2003;11(3):223-228.

47. Osorio R, Ceballos L, Tay F, Cabrerizo-Vilchez MA, Toledano M. Effect of sodium hypochlorite on dentin bonding with a polyalkenoic acid-containing adhesive system. J Biomed Mater Res 2002;60:316-324.

48. Yiu CKY, García-Godoy F, Tay FR, Pashley DH, Imazato S, King NM, et al. A nanoleakage perspective on bonding to oxidized dentin. J Dent Res 2002;81(9):628-632.

49. Saboia VPA, Nato F, Mazzoni A, Orsini G, Putignano A, Giannini M, et al. Adhesion of a twostep etch-and-rinse adhesive on collagen-depleted dentin. J Adhes Dent. 2008;10:419-422.

50. Baseggio W, Consolmagno EC, de Carvalho FLN, Ueda JK, Schmitt VL, Formighieri LA, et al. Effect of deproteinization and tubular occlusion on microtensile bond strength and marginal microleakage of resin composite restorations. J Appl Oral Sci. 2009;17(5):462-466.

51. dos Santos PH, Sinhoreti MAC, Consani S, Sorbinho LC, Adabo GL, Vas LG. Effect of cyclic compressive loading on the bond strength of an adhesive system to dentin after collagen removal. J Adhes Dent. 2005;7:127-131.

52. Perdigão J, Lopes M, Geraldeli S, Lopes GC, García-Godoy F. Effect of a sodium hypochlorite gel on dentin bonding. Dent Mater. 2000;16(5):311-323.

53. Uceda-Gomez N, Loguercio AD, Moura SK, Grande RHM, Odas M, Reis A. Long-term bond strength of adhesive systems applied to etched and deproteinized dentin. J Appl Oral Sci. 2007;15(6):475-479. 
54. Manjunath MK, Vinutha M. In vitro evaluation of the effect of sodium hypochlorite on shear bond strength of dentin bonding agent on demineralized and remineralized dentin. Journal of Conservative Dentistry 2007;10(2):64-73.

55. Correr GM, Ruppin-Rontani RM, Correr-Sobrinho L, Sinhoreti MAC, Consani S. Effect of sodium hypchlorite on dentin bonding in primary teeth. J Adhes Dent. 2004;6:307-312.

56. Montagner AF, Skupien JA, Borges MF, Krejci I, Bortolotto T, Henrique A. Effect of sodium hypochlorite as dentinal pretreatment on bonding strength of adhesive systems. Indian Journal of Dental Research 2015;26(4):416-420.

57. Lisboa DS, Santos SV, Griza S, Rodrigues JL, Faria-e-Silva AL. Dentin deproteinization effect on bond strength of self-adhesive resin cements. Braz Oral Res. 2013;27(1):73-75.

58. Aguilera F-S, Osorio R, Osorio E, Moura P, Toledano M. Bonding efficacy of an acetone/based etch-and-rinse adhesive after dentin deproteinization. Med Oral Patol Oral Cir Bucal. 2012;17(4):e649654.

59. de-Souza FB, Silva CHV, Dibb RGP, Delfino CS, Beatrice LCd-S. Bonding performance of different adhesive systems to deproteinized dentin: microtensile bond strength and scanning electron microscopy. J Biomed Mater Res B Appl Biomater. 2005;75(1):158-167.

60. Sauro S, Mannocci F, Toledano M, Osorio R, Pashley DH, Watson TF. EDTA or H3PO4/NaOCl dentine treatments may increase hybrid layers' resistance to degradation: A microtensile bond strength and confocal-micropermeability study. Jo u r $n$ a I of De $n$ t i s t ry 2009;37:27 29-28 28.

61. Goncalves LS, consani S, Sinhoreti MAC, Schneider LFG, Saboia VPA. Effect of storage and compressive cycles on the bond strength after collagen removal. Operative Dentistry 2009;34-36:681687.

62. Arias VG, Bedran-de-Castro AKB, Pimenta LA. Effects of sodium hypochlorite gel and sodium hypochlorite solution on dentin bond strength. J Biomed Mater Res Part B: Appl Biomater 2005;72B:339-344.

63. Taniguchi G, Nakajima M, Hosaka K, Iwamoto N, Ikeda M, Foxton RM, et al. Improving the effect of $\mathrm{NaOCl}$ pretreatment on bonding to caries-affected dentin using self-etch adhesives. $\mathrm{j}$ o $\mathrm{u} \mathrm{r}$ a l of de $n \mathrm{t}$ i s t ry 2009;37:76 79-77 75 .

64. Stevens CD. Immediate shear bond strength of resin cements to sodium hypochlorite-treated dentin. J Endod 2014;40:1459-1462.

65. Cecchin D, Farina AP, Galafassi D, Barbizam JVB, Corona SAM, Carlini-Júnior B. Influence of sodium hypochlorite and EDTA on the microtensile bond strength of a self-etching adhesive system. J. Appl. Oral Sci. 2010;18(4):385-389.

66. Hassan AM, Goda AA, Baroudi K. The effect of different disinfecting agents on bond strength of resin composites. International Journal of Dentistry 2014;2014.

67. Mohammad-Esmaeel Ebrahimi-Chaharom SK, Narmin Mohammadi, Parnian-Alizadeh Oskoee, Mehdi Daneshpuy, and Mahmoud Bahari. Effect of sodium ascorbate on the bond strength of all-inone adhesive systems to NaOCl-treated dentin. J Clin Exp Dent. 2015;7(5):e595-e599.

68. Gonulol N, Kalyoncuoglu K, Ertas E. Effect of sodium ascorbate on dentin bond strength after treatment with oxidizing root canal irrigants. Journal of Dental Sciences 2015;10:139-144.

69. Farina AP, Cecchin D, Barbizam JVB, Carlini-Júnior B. Influence of endodontic irrigants on bond strength of a self-etching adhesiveae. Aust Endod J 2011;37:26-30.

70. Nassar M, Awawdeh L, Jamleh J, Sadr A, Tagami J. Adhesion of epiphany self-etch sealer to Dentin Treated with intracanal irrigating solutions. J Endod 2011;37:228-230.

71. Abo T, Asmussen E, Uno S, Taggmi J. Short- and long-term in vitro study of the bonding of eight commercial adhesives to normal and deproteinized dentin. 2006;Acta Odontologica Scandinavica(64).

72. Saber S-EM, El-Askary FS. The outcome of immediate or delayed application of a single-step self-etch adhesive to coronal dentin following the application of different endodontic irrigants. Eur J Dent 2009;3:83-89. 
73. Kunawarote S, Nakajima M, Shida K, Kitasako Y, Foxton RM, Tagami J. Effect of dentin pretreatment with mild acidic $\mathrm{HOCl}$ solution on microtensile bond strength and surface $\mathrm{pH}$. jo $\mathrm{u} \mathrm{r} \mathrm{n}$ a I of de $\mathrm{n} \mathrm{t}$ i s t ry 2010;38:26 21-26 28.

74. Kmabara K, Nakajima M, Hoska K, Takahash M, Thanatvarakorn O, Ichinose S, et al. Effect of smear layer treatment on dentin bond of self-adhesive cements. Dental Materials Journal 2012;31(6):980-987.

75. Ayad MF, Garcia-Godoy F. Effect of lactic acid irrigant on shear bond strength of Epiphany adhesive sealer to human dentin surface. Oral Surg Oral Med Oral Pathol Oral Radiol Endod 2010;109:e100-e106.

76. Kasraei S, Azarsina M, Khamverdi Z. Effect of Ethylene diamine tetra acetic acid and sodium hypochlorite solution conditioning on microtensile bond strength of one-step self-etch adhesives. J Conserv Dent. 2013;16(3):243-246.

77. Sasafuchi Y, Nikaido T, Tagami J. Effect of chemical irrigants and medicaments for endodontic treatment on dentin bonding. Int China Dent J 2003;3:7-12.

78. Prasansuttiporn T, Nakajima M, Kunawarote S, Foxton RM, Tagami J. Effect of reducing agents on bond strength to $\mathrm{NaOCl}$-treated dentin. Dent Mater. 2011;27(3):229-234.

79. Vongphan N, Senawongse P, Somsiri W, Harnirattisai C. Effects of sodium ascorbate on microtensile bond strength of total-etching adhesive system to $\mathrm{NaOCl}$ treated dentine. Journal of Dentistry 2005;33:689-695.

80. Bhat Gorwich S, Mohan B, Lackshimanarayana L, Savadamoorthi. A comparative evaluation of effect of sodium hypochlorite on microtensile bond strength of three different bonding agents to the lateral wall of pulp chamber : An in vitro study. International Research Jorunal of Pharmacy 2013;4(3):156-159.

81. Ozturk B, Ozer F. Effect of $\mathrm{NaOCl}$ on bond strengths of bonding agents to pulp chamber lateral walls. J Endod. 2004;30(5):362-365.

82. Santos JN, Carrilho MRd-O, De Goes MF, Zaia AA, Gomes BPFd-A, de Souza-Filho FJ, et al. Effect of chemical irrigants on the bond strength of a self-etching adhesive to pulp chamber dentin. J Endod 2006;32:1088-1090.

83. Shrestha D, Wu W-C, He K-Y, Wei X, Ling J-Q. Effect of sodium ascorbate on degree of conversion and bond strength of realseal se to sodium hypochlorite treated root dentin. Dent Mater J 2013;32(1).

84. Morris MD, Lee KW, Agee KA, Bouillaguet S, Pashley DH. Effects of sodium hypochlorite and RC-prep on bond strengths of resin cement to endodontic surfaces. J Endod. 2001;27(12):753-757.

85. Manimaran VS, Srinivasulu S, Rajesh Ebenezar A, Mahalaxmi S, Srinivasan N. Application of a proanthocyanidin agent to improve the bond strength of root dentin treated with sodium hypochlorite. J Conserv Dent. 2011;14(3):306-308.

86. Ari $\mathrm{H}$, Yaşar E, Belli S. Effects of $\mathrm{NaOCl}$ on bond strengths of resin cements to root canal dentin. J Endod. 2003;29(4):248-251.

87. Stelzer R, Schaller H-G, Gernhardt CR. Push-out Bond Strength of RealSeal SE and AH Plus after Using Different Irrigation Solutions. J Endod 2014;40:1654-1657.

88. Haragushiku GA, Sousa-Neto MD, Silva-Sousa YTC, Alfredo E, Silva SC, Silva RG. Adhesion of endodontic sealers to human root dentine submitted to different surface treatments. Photomedicine and Laser Surgery 2010;28(3):405-410.

89. Ishizuka T, Kataoka H, Yoshioka T, Suda H, Iwasaki N, Takahash $\mathrm{H}$, et al. Effect of $\mathrm{NaClO}$ treatment on bonding to root canal dentin using a new evaluation method. Dental Materials Journal 2001;20(1):24-33.

90. Boruziniat A, Arjmand N, Atoufi A. Evaluation of the effect of sodium hypochlorite irrigant on pull-out bond strength of FRC posts using different resin cements. Jorunal of Dental Materials and Techniques 2015;4(1):43-48. 
91. Lacerda AJF, Gullo MA, Xavier ACC, Pucci CP, Carvalho CAT, Hutala MFRL. Influence of ultrasound and irrigant solutions on the bond strength of glass fiber posts to root canal dentine. Braz Dent Sci 2013;16(1):53-58.

92. Khoroushi M, Kachuei M. Pull-out bond strength of a self-adhesive resin cement to NaOCltreated root dentin: effect of antioxidizing agents. Restor Dent Endod 2014;39(2):95-103.

93. Arısu HD, luKıvanç BDH, lam BCS, Simsek E, Görgül G. Effect of post-space treatments on the push-out bond strength and failure modes of glass fibre posts. Aust Endod J 2013;39:19-24.

94. Alkhudhairy FI, Bin-Shuwaish MS. The effect of sodium hypochlorite and resin cement systems on push-out bond strength of cemented fiber posts. Pak J Med Sci 2016;32(4):905-910.

95. Faria-e-Silva AL, Menezes Md-S, Silva FP, dos Reis GR, de Moraes RR. Intra-radicular dentin treatments and retention of fiber posts with selfadhesive resin cements. Braz Oral Res., (São Paulo) 2013;27(1):14-19.

96. Bueno CEd-S, Pelegrine RA, Silveira CFd-M, Bueno VCPd-S, Alves Vd-O, Cunha RS, et al. The impact of endodontic irrigating solutions on the push-out shear bond strength of glass fiber posts luted with resin cements. Gen Dent. 2016;64(1):26-30.

97. Bitter K, Hambarayan A, Neumann K, Blunck U, Sterzenbach G. Various irrigation protocols for final rinse to improve bond strengths of fiber posts inside the root canal. Eur J Oral Sci 2013;121:349354.

98. Ertas H, Ok E, Uysal B, Arslan H. Effects of different irrigating solutions and disinfection methods on push-out bond strengths of fiber posts. Acta Odontologica Scandinavica 2014;72(8):783787.

99. Pelegrine RA, De Martin AS, Cunha RS, Pelegrine AA, Bueno CEd-S, Paulo S. Influence of chemical irrigants on the tensile bond strength of an adhesive system used to cement glass fiber posts to root dentin. Oral Surg Oral Med Oral Pathol Oral Radiol Endod

Endod 2010;110:e73-e76.

100. Haragushiku GA, Back EDEE, Tomazinho PH, Filho BF, Furuse AY. Influence of antimicrobial solutions in the decontamination and adhesio of glass-fiber posts to root canals. J Appl Oral Sci 2015;23(4):436-641.

101. Kaif M, Bissu R. Influence of irrigating solutions on push-out bond strenght of intraradicular posts to dentine. Int. J. Dental Sc. 2016;18(1):73-81.

102. Cecchin D, Almeida JFA, Gomes BPFA, Zaia AA, Ferraz CCR. Deproteinization technique stabilizes the adhesion of the fiberglass post relined with resin composite to root canal. J Biomed Mater Res Part B 2012;100B:577-583.

103. Inoue $\mathrm{S}$, Murata $\mathrm{Y}$, Sano $\mathrm{H}$, Kashiwada T. Effect of $\mathrm{NaOCl}$ treatment on bond strength between indirect resin core-buildup and dentin. Dent Mater J. 2002;21(4):343-354.

104. Mao H, Chen Y, Yip KH-K, Smales RJ. Effect of three radicular dentine treatments and two luting cements on the regional bond strength of quartz fibre posts. Clin Oral Invest 2011;15:869-878. 105. Varela SG, Rábade LB, Lombardero PR, Sixto JM, Bahillo JD, Park SA. In vitro study of endodontic post cementation protocols that use resin cements. J Prosthet Dent. 2003;89(2):146-153.

106. Furuse AY, Cunha LF, Baratto SP, Leonardi DP, Haragushiku GA, Gonzaga CC. Bond strength of fiber-reinforced posts to deproteinized root canal dentin. J Contemp Dent Pract. 2014;15(5):581-586. 107. da Cunha LF, Furuse AY, Mondelli RFL, Mondelli J. Compromised bond strength after root dentin deproteinization reversed with ascorbic acid. J Endod. 2010;36(1):130-134.

108. Khoroushi M, Kachuei M. Pull-out bond strength of a self-adhesive resin cement to $\mathrm{NaOCl}-$ treated root dentin: effect of antioxidizing agents. Restor Dent Endod. 2014;39(2):95-103. 